IZA DP No. 9868

Disincentive Effects of Unemployment Benefits and the Role of Caseworkers

Johannes F. Schmieder

Simon Trenkle

April 2016 


\title{
Disincentive Effects of Unemployment Benefits and the Role of Caseworkers
}

\author{
Johannes F. Schmieder \\ Boston University, \\ NBER, IZA and CESIfo \\ Simon Trenkle \\ Institute for Employment Research (IAB)
}
Discussion Paper No. 9868
April 2016

IZA

P.O. Box 7240

53072 Bonn

Germany

Phone: +49-228-3894-0

Fax: +49-228-3894-180

E-mail: iza@iza.org

\begin{abstract}
Any opinions expressed here are those of the author(s) and not those of IZA. Research published in this series may include views on policy, but the institute itself takes no institutional policy positions. The IZA research network is committed to the IZA Guiding Principles of Research Integrity.

The Institute for the Study of Labor (IZA) in Bonn is a local and virtual international research center and a place of communication between science, politics and business. IZA is an independent nonprofit organization supported by Deutsche Post Foundation. The center is associated with the University of Bonn and offers a stimulating research environment through its international network, workshops and conferences, data service, project support, research visits and doctoral program. IZA engages in (i) original and internationally competitive research in all fields of labor economics, (ii) development of policy concepts, and (iii) dissemination of research results and concepts to the interested public.
\end{abstract}

IZA Discussion Papers often represent preliminary work and are circulated to encourage discussion. Citation of such a paper should account for its provisional character. A revised version may be available directly from the author. 


\title{
ABSTRACT \\ Disincentive Effects of Unemployment Benefits and the Role of Caseworkers*
}

\begin{abstract}
A large literature has documented that the unemployment duration of unemployed individuals increases with the generosity of the unemployment insurance (UI) system, which has been interpreted as the disincentive effect of $U I$ benefits. However, unemployed workers typically also have caseworkers assigned who are monitoring and assisting the job search efforts. These caseworkers may respond to differences in UI eligibility by shifting resources (financial or time) between unemployed individuals in order to counteract the moral hazard effect of UI benefits or to focus resources to where they have the largest effect. Depending on the motivations of the caseworker, the effectiveness of caseworker resources and the complementarity between these resources and $\mathrm{UI}$ benefits, the typical estimates of the disincentive effects of UI may be biased upwards or downwards in studies that compare workers within the same UI agency. We estimate whether caseworkers respond to the generosity of UI eligibility using a sharp regression discontinuity (RD) design in Germany, where potential UI durations vary with age. We show that across a wide variety of measures, including training programs, wage subsidies, personal meetings and sanctions, UI caseworkers do not treat unemployed with different eligibility differently. At best we find a very small effect that workers with shorter eligibility close to the exhaustion point are more likely to be assigned to training programs that prolong their UI eligibility. The typical RD estimates of the UI disincentive effects thus seem to be valid estimates.
\end{abstract}

JEL Classification: J65

Keywords: unemployment benefits, unemployment insurance, caseworkers, active labor market programs

Corresponding author:

Johannes F. Schmieder

Department of Economics

Boston University

270 Bay State Road

Boston, MA 02215

USA

E-mail: johannes@bu.edu

\footnotetext{
* We would like to thank Stefan Bender, Kevin Lang, and Regina Riphahn as well as seminar participants at the University of Erlangen-Nuremberg for many helpful comments. All errors are our own.
} 


\section{Introduction}

A large literature has documented that unemployed workers who face more generous unemployment insurance (UI) benefit levels and eligility durations take longer to return to employment. This has typically been interpreted as the moral hazard effect of UI benefit: 1 , where individuals respond to the reduction in the marginal benefit of finding a job relative to remaining unemployed by lowering their search effort. Unemployed workers, however, are also influenced by caseworkers of the UI agencies, who are typically tasked with monitoring job search effort as well as with providing various types of support to the unemployed, such as through job referrals, various active labor market programs or by providing advice and motivation. Since caseworkers have limited resources in terms of time, financial means for active labor market programs and vacancies that they can refer workers to, they may respond to differences in UI eligibility across workers by targeting their efforts. If these efforts then have a direct effect on unemployment durations, this could lead to substantial biases in estimates of the disincentive effects of UI benefits. Some of the most convincing empirical estimates of the effect of UI eligibility are based on regression discontinuity designs (Lalive et al., 2006, Card et al., 2007a; Lalive, 2008, Schmieder et al., 2012a) and regression kink designs (Landais, forthcoming; Card et al., 2015a, forthcoming). However, these are precisely the settings where the potential bias from caseworker responses to UI eligibility may be particularly severe, since these designs effectively compare workers in the same labor market and plausibly within the same caseworker.

In this paper we provide the first estimates - to the best of our knowledge - whether UI caseworkers respond to differences in UI eligibility across unemployed workers. We use the fact that in Germany potential UI benefit durations are a function of the exact age of claiming UI benefits where durations increase discontinuously from 12 to 15 months of benefits at age 50. As has been shown in other studies (Schmieder et al., 2012a, forthcoming) for earlier time periods in Germany, this discontinuity gives rise to a substantial decrease

\footnotetext{
${ }^{1}$ Or a combination of a moral hazard and income effect (Chetty 2008).
} 
in job finding hazards and a corresponding increase in unemployment durations. Using the universe of social security data in Germany merged to a unique new dataset on active labor market program participation, caseworker activities (such as personal meetings with the unemployed, the signing of integration contract, and vacancy referrals), and sanctions, we analyze whether caseworkers respond to the increase in UI eligibility at the age threshold. An important aspect of the empirical analysis is, that while UI eligibility is determined at the start of the UI spell, caseworkers interact with the unemployed throughout the entire unemployment spell and may assign them into different programs at various points in time. In the empirical part we therefore carefully deal with this dynamic aspect of the caseworker actions and we present both cross-sectional results - showing the effect of UI eligibility on total program participation and caseworker interactions - as well as dynamic results, showing the effect by month since the start of the UI spell.

A priori, UI eligibility can affect how caseworkers allocate their resources in various ways, depending on the objective function of the caseworker as well as the effectiveness of the resources the caseworker has at her disposition. For example caseworkers might be trying to minimize the average time until their assigned cases get back to work. If assignment into active labor market programs increases the job finding rate among the unemployed, then the caseworker would focus these resources on workers who are most responsive to these programs, which might be individuals with shorter durations who have more to gain from participating in these programs, or it might be individuals with longer UI durations, perhaps because the threat of a training program might be particularly effective for them to overcome the larger disincentive effect from UI. Similarly, other caseworker instruments like sanctions, monitoring or wage subsidies might be complements or substitutes with UI benefits which could lead to positive or negative correlations between caseworker activities and UI generosity. Furthermore, caseworkers might also have other objective functions, which can also have ambiguous effects on how they allocate their resources. For example caseworkers might be maximizing something like a Rawlsian social welfare function and thus attempt to focus their resources on the person with lower UI benefits in order to compensate them for 
the disadvantage of lower benefits. Furthermore caseworkers could be focused on assigning workers to ALMP programs who are most likely to find a job afterwards (with or without the training program), thus leading to the appearance that the program was successful ${ }^{2}$ In short, depending on the type of caseworker instrument, the objective function of the caseworker, and the complementarity between UI benefits and caseworker actions, the effect of UI generosity on caseworker actions is ambiguous. In the next section, we will lay out these various ways caseworkers might be motivated to allocate their resources and derive some empirical tests from them.

The paper is related to the large literature on the effectiveness of active labor market programs and other dimensions of caseworker actions. Card et al. (2010) and Card et al. (2015b) provide an excellent overview over the literature. While results are heterogeneous across studies and some programs, such as public employment programs, may not be particulary effective, others, such as job search assistance and some training programs, seem to succeed in getting workers back into jobs over the short or medium run. Other papers (e.g. Berg et al., 2004, Abbring et al., 2005, Lalive et al., 2005, Svarer, 2007), have evaluated the use of sanctions and found that they are quite successful in increasing transition rates back into employment. A growing body of research has also documented that often the threat of being sent to a training program may be enough to induce individuals to return to work, thus seemingly serving as a monitoring device (e.g. Black et al., 2003, Giulietti et al. 2011). Overall, there is substantial evidence on the effectiveness of different caseworker actions, but less is known about the motivations and goals of caseworkers. Boockmann et al. (2013) provide survey evidence on caseworkers' motivations and strategies, but do not analyze quantitatively what factors influence caseworker actions. In contrast we investigate whether caseworkers respond to specific institutional features of the UI system, using a well defined natural experiment.

This paper complements the research estimating the disincentive effects of UI benefits. While this is a long line of research (with early seminal papers such as Moffitt, 1985 or Meyer,

\footnotetext{
${ }^{2}$ See Heckman et al. (1997) and Bell and Orr (2002) for evidence and discussion of such a "creaming" effect in training programms.
} 
1990), it has received a lot of new interest with the advent of large administrative datasets and the rise of econometric methods like regression discontinuity (e.g. Lalive, 2008; Lalive et al. 2006, Card et al., 2007a; Schmieder et al., 2012a b; Johnston and Mas, 2015) and - more recently - regression kink designs (Landais, forthcoming; Card et al., 2015a, forthcoming) $\mathrm{S}^{3}$ The advantage of these designs is that they exploit policy features to isolate variation in UI generosity which is plausibly orthogonal to individual characteristics (observed and unobserved) and uncorrelated with other policy parameters, in many ways almost mimicking a randomized controlled trial. However these papers do not observe to what extent caseworkers and employment agencies themselves are responding to the policy variation by shifting various resources between different groups of workers. The nature of these designs suggests that the workers in the implicit treatment and control groups may well be assigned to the same caseworker, which implies that the problem of bias from caseworker actions may be particularly severe. Without information on caseworker activities it is impossible to gauge the possible magnitude from this bias, but the possibility that actions by intermediaries (with good intentions) may severely complicate the interpretation of differences between individuals with different 'treatments' has been recognized since the early days of statistical research such as in Student's (1931) famous critique of the Lanarkshire milk experiment. The main contribution of this paper is therefore to analyze the validity of the implicit assumption in these studies that caseworker actions are not confounding the estimates of the disincentive effects of UI, at least in the specific context that we are studying here.

The next section will discuss a simple framework for understanding the role of caseworkers and how they may bias estimates of the disincentive effects of UI. Section 3 provides institutional background on the role of UI caseworkers in Germany and describes our data. In section 4 we explain our empirical method based on an age discontinuity in Germany and provide evidence that this gives rise to a valid regression discontinuity design. Section 5 presents the main empirical results and section 6 concludes.

\footnotetext{
${ }^{3}$ See Schmieder and von Wachter $\sqrt{2015}$ for a review of this recent literature.
} 


\section{Theoretical Framework}

We describe a simple stylized framework here to illustrate how the actions of caseworkers may bias estimates of the disincentive effects of UI and what would determine the direction of the bias. Consider a world where individuals $i$ are unemployed at the beginning of the (single) period. The unemployed search for a job and choose search effort $e_{i}$ for which they face a cost of $\psi\left(e_{i}\right)$. If they do find a job, they immediately start working and receive a wage $w$, otherwise they are unemployed for the period and receive UI benefits $b_{i}$, which may vary across individuals. The utility function is given as $u($.$) . Workers are subject to 'treatment'$ by a caseworker measured as $\omega_{i}$, which encompasses any kind of actions at the disposal of the caseworker, such as job search monitoring, vacancy referrals or ALMP. Furthermore the probability $s_{i}$ of finding a job is a function of effort and caseworker resources: $s_{i}=s\left(e_{i}, \omega_{i}\right)$. Workers are maximizing expected utility:

$$
V_{i}=\max _{e_{i}} s\left(e_{i}, \omega_{i}\right) u(w)+\left(1-s\left(e_{i}, \omega_{i}\right)\right) u\left(b_{i}\right)-\psi\left(e_{i}\right)
$$

The first order condition for the worker is

$$
\frac{\partial s\left(e_{i}, \omega_{i}\right)}{\partial e_{i}}\left(u(w)-u\left(b_{i}\right)\right)-\psi^{\prime}\left(e_{i}\right)=0
$$

This function implicitly defines an optimal search effort function $\xi\left(b_{i}, \omega_{i}\right)$, so that workers are finding a job with probability:

$$
s_{i}=s\left(\xi\left(b_{i}, \omega_{i}\right), \omega_{i}\right)
$$

Consider the following log linearized approximation of equation (1):

$$
s_{i}=\eta b_{i}+\pi \omega_{i}+X_{i} \beta+\varepsilon_{i}
$$

The empirical literature typically estimates a version of equation 2 that omits the $\omega_{i}$-term 
in order to identify a parameter such as $\eta$, the effect of UI benefits on the job finding hazard. Typical estimation strategies such as RDD or RKD are focused on isolating variation (by selecting appropriate samples and controls $\left.X_{i}\right)$ such that $\operatorname{Cov}\left(b_{i}, \varepsilon_{i} \mid X_{i}\right)=0$. However, if caseworkers allocate resources across unemployed workers taking $b_{i}$ into account this would lead to $\operatorname{Cov}\left(\omega_{i}, b_{i} \mid X_{i}\right) \neq 0$. In this case, as highlighted by equation (2), not controlling for $\omega_{i}$ will lead to an omitted variable bias when estimating $\eta$.

Suppose the allocation of resources among the unemployed can be described using the following linear model:

$$
\omega_{i}=\delta b_{i}+X_{i} \gamma+\epsilon_{i}
$$

If $\delta \neq 0$, then estimation of equation (2) without controlling for $\omega_{i}$ will lead to a biased estimate of $\eta$. The sign of $\delta$ will determine the sign and the magnitude of this bias.

To see what kind of values $\delta$ might plausibly take, consider a situation where each caseworker is assigned two unemployed individuals $i=1,2$. Furthermore the overall amount of resources (time, money, vacancies, ...) of the caseworker are limited to $R=\omega_{1}+\omega_{2}$. The caseworker chooses an allocation of his resources to maximize an objective function subject to this budget constraint:

$$
\max _{\omega_{1}, \omega_{2}}=W\left(\omega_{1}, \omega_{2}\right) \text { s.t. } R=\omega_{1}+\omega_{2}
$$

How caseworkers allocate their resources will depend crucially on the objective function $W$, as well as on how resources actually affect the unemployed. We will consider several stylized cases and highlight in each of these cases how resource allocation would be correlated with benefit levels.

First, consider the unemployment-minimizer, who wants to reduce average unemployment durations as much as possible. Such a caseworker can be described as maximizing the objective function $W\left(\omega_{1}, \omega_{2}\right)=s_{1}+s_{2}=\xi\left(b_{1}, \omega_{1}\right)+\xi\left(b_{2}, \omega_{2}\right)$. If $b_{i}$ and $\omega_{i}$ are substitutes, that is if $\frac{\partial^{2} \xi}{\partial b_{i} \partial \omega_{i}}<0$, then at the optimum $\omega_{i}$ will be negatively related to UI benefits. On the other hand if $b_{i}$ and $\omega_{i}$ are complements, they will be positively related. The assumption 
of substitutes may be plausible in the case of job search monitoring or sanctions: a worker with low UI benefits may already be searching relatively hard for jobs, with little additional increase in the job finding probability if he is monitored or sanctioned more, while a worker with high UI benefit levels may be more responsive. On the other hand $b_{i}$ and $\omega_{i}$ may plausibly be complements in the case of training programs or wage subsidies. A worker who is very motivated (due to low UI payments) may be more willing to learn new skills in a training program or to look for jobs where he might benefit from a wage subsidy. Therefore if caseworkers are trying to minimize overall unemployment durations, this would lead to a correlation between benefit generosity and caseworker resources, where the sign will depend on the search effort function of the worker.

Next, consider the caseworker who wants to maximize perceived resource efficiency, where we define perceived resource efficiency as the unconditional correlation between the job finding probability and caseworker resources. The idea is that a naive principal who is overlooking the caseworker might use this correlation as a simple measure for whether caseworkers are using their resources efficiently. The German UI agency for example regularly publishes statistics (on the level of local UI agencies) of the fraction of people who are participating in ALMP who then find a job within a year. Such an objective function can be expressed as: $W\left(\omega_{1}, \omega_{2}\right)=s_{1} \omega_{1}+s_{2} \omega_{2}$. With such an objective function the caseworker would - at least to a first order approximation - simply focus resources to the person where $\xi\left(b_{i}, \omega_{i}\right)$ is the highest, which may (though not necessarily) be the opposite of what the unemployment-minimizer would do. Since search effort is decreasing in $b_{i}$, this would tend to generate a negative association with caseworker resources.

Third, consider the welfarist caseworker, who is maximizing a social welfare function defined over individual utilities of the unemployed. This could include a Rawlsian social welfare function such as: $W=\min \left\{V_{1}\left(\omega_{1}\right), V_{2}\left(\omega_{2}\right)\right\}$ or a Utilitarian social welfare function such as: $W=V_{1}\left(\omega_{1}\right)+V_{2}\left(\omega_{2}\right)$. In the Rawlsian case, the caseworker would also tend to focus resources on the disadvantaged unemployed with low UI benefits, leading to a negative relationship between $b_{i}$ and $\omega_{i}$, while in the Utilitarian case the sign is ambiguous and, 
depending on whether $b_{i}$ and $\omega_{i}$ are complements or substitutes, may go in the opposite direction.

Finally, consider the bureaucratic caseworker, who simply follows guidelines (explicit or implicit) where resources are allocated according to observable worker characteristics $X_{i}$. For example all workers are treated equally, or workers are supported / monitored purely based on observable characteristics such as age, education, qualification etc. In this case we have that: $\operatorname{Cov}\left(\omega_{i}, s_{i} \mid X_{i}\right)=0$, and the typical estimates of $\eta$ would not be biased.

The main goal of this paper is to provide consistent estimates of $\delta$ in equation (3), which will then allow us to estimate the bias from estimating equation (2) without controlling for $\omega_{i}$. Furthermore, as can be seen from the discussion, the sign of $\delta$ is informative about the objective function of the caseworkers and may provide insights into the likely complementarity of $\omega_{i}$ and $b_{i}$ in the search effort function. It should be noted that in practice caseworker resources are a vector with many components and that it is certainly possible that caseworkers have differing objectives for different resources and that the complementarity between $\omega_{i}$ and $b_{i}$ varies across different types of caseworker actions. We will get back to this in the interpretation of our empirical results.

\section{Institutional Background and Data}

\subsection{Unemployment insurance in Germany}

Workers in Germany are eligible to receive UI benefits if they are unemployed and have been employed for at least 12 months in the previous two years. The replacement rate is 60 percent of the pre-unemployment wage (67 percent if the person has children) up to a wage of 5300 Euro per month in 2008.4 Eligibility duration depends on the number of months worked in the previous 5 years before claiming UI benefits, as well as the age at the time of claiming. From 2008 onwards, the maximum potential benefit duration (PBD) of UI was 12 months for individuals below age 50 at the time of claiming UI benefits, 15 months for individuals

\footnotetext{
${ }^{4}$ The cap is lower in East Germany and increases over time, roughly at the inflation rate. The maximum wage that counts for UI benefit calculations is located approximately at the 85th percentile of the wage distribution, but rarely binding for the unemployed who typically come from lower paid jobs.
} 
age 50 to 54,18 months for individuals age 55 to 57 and 22 months for individuals age 58 and older $5^{5}$ We will focus on workers who are close to the age 50 threshold when they claim UI benefits and who have worked for at least 30 months in the previous 5 years so that they are eligible to the maximum benefit duration 6

After individuals exhaust UI benefits the unemployed can apply for a means tested second tier benefit level called UI benefits II (UIB II). $7^{7}$ The monthly benefits in this second tier program are around 370 Euro per person in addition to rent and health insurance. Individuals who are working while receiving UIB II face implicit marginal tax rates of around 90 percent. Depending on pre unemployment income, asset levels and possibly spousal income, benefits levels in UIB II may be anywhere between substantially lower than regular UI benefits to quite similar.

Workers who quit their jobs, lose them at their own fault, or fail to register for job search prior to the UI claim may be subject to sanctions of varying durations, that is periods where they do not receive UI benefits. We restrict our sample to individuals who receive UI benefits within less than 3 months after job separation, which excludes voluntary quits.

\subsection{Caseworkers}

Unemployed individuals are required to register for job search when they get notified of a lay-off and have to appear at their local employment agency (Arbeitsagentur) in order to apply for UI benefits before they can claim them. 8 At the first appointment they are

\footnotetext{
${ }^{5}$ The maximum PBD is the maximum duration someone can be eligible for at the beginning of the spell. This maximum can implicitly increase throughout the spell through participation in active labor market programs, since while in such a program the unemployed continue to receive UI benefits, but use up only 1 day of PBD per 2 days of program participation. We will get back to this in the empirical section.

${ }^{6}$ Below age 50 , working for 24 months in the previous 5 years would be enough to qualify for the maximum of 12 months of benefits, but in order to have a comparable sample we impose the 30 months requirement on both sides of the cutoff. If individuals had UI spells in the previous 5 years the clock for calculating UI benefits would be reset and we therefore require that they have worked for at least 30 months since the end of that UI spell.

${ }^{7}$ UIB II was introduced during the Hartz reforms in 2003/2004 which merged the older systems of unemployment benefits and unemployment assistance. See Eichhorst and Marx (2011) for a detailed description of the reforms.

${ }^{8}$ There are 160 employment agency districts, each comprising around 2-3 counties. Typically there is one central agency in a district as well as several smaller local branches.
} 
assigned a caseworker whose task it is to process the benefit application, to advise and support the unemployed on job search, and to monitor job search efforts. Support can come in the form of simply discussing possible job options and application strategies, as well as by offering participation in active labor market programs (such as training programs, public employment programs or wage subsidies for potential jobs). Employment agencies also offer a platform for vacancy postings and they are used directly by employers to look for possible workers. Caseworkers have access to vacancies offered by employers and may refer them to specific unemployed workers. Apart from these supportive measures caseworkers monitor job search and can sanction individuals with benefit cuts if they fail to comply with search requirements. The duration of these cuts varies from one week (for example for delayed job search registration) to up to twelve weeks (for voluntary job quits). Sanctions are used to punish unemployed that do not use the offered support by the caseworker. Refusing to participate in an active labor market program, cancelling a started program or rejecting a vacancy referral can be punished with a benefits cut of three weeks. A lack of individual initiative in looking for a job can be punished with a cut of two weeks. The duration of benefit cuts increases with the number of sanctions. For example, the first two times a worker refuses a vacancy referral benefits are cut for three weeks, but this goes up to twelve weeks after the third refusal. Benefit cuts from different sanctions are additive up to a total duration of benefit cuts of 21 weeks, when benefits are cut completely, see Hofmann (2012).

During the first meeting the caseworker assesses how easy it will be for the unemployed to find back into employment and assigns them to one of various profiles. These profiles may then be used to guide integration strategies by the local UI agency, though there is a lot of freedom remaining how caseworkers may use them. Caseworkers and unemployed typically meet in regular intervals to discuss job search progress, devise new application strategies and, potentially, to monitor search efforts by the unemployed. The frequency of these meetings is up to the caseworker 9 .

\footnotetext{
${ }^{9}$ This is consistent with the heterogeneous meeting frequency we find between workers. For the number of meetings we find for the 75 th percentile 0.44 meetings per months unemployed as opposed to 0.2 meetings for the 25th percentile in our main sample.
} 
Since the Hartz Reforms, caseworkers and the unemployed are required to sign a so called integration contract, an agreement that specifies the expectations what the unemployed worker is supposed to do each week in order to find a job as well as the support she gets from the caseworker. On the worker side, it can for example specify the number of applications she agrees to send in a given time. On the caseworker side, it can specify the founding of a targeted training program or to cover costs related to the application process. The contract usually specifies the target occupation and task, as well as the regional area in which the worker is looking for jobs. These contracts are legally binding for both sides and are supposed to be updated every six months (Schütz et al., 2011).

\subsection{Data}

We use data from the Integrated Employment Biographies (IEB) of the German Social Security system, which covers all social security liable employment relationships in Germany as well as information on unemployment benefits and registered job search status. We extract a sample of all individuals who enter UI benefits between April 2008 and June 2010 who are between age 45 and 55 at the age of claiming UI benefits and who are eligible to the maximum benefit duration of their age group. For the main regression analysis we furthermore restrict the sample to a 2 year window around the age cutoff. For each UI spell we know the duration of receiving UI benefits, the duration of registered job search and nonemployment duration, that is time until the next employment spell that is covered in the dataset.10 Furthermore we have information on participation in active labor market programs, and can infer sanctions from benefits spells where no UI benefits are paid.

We supplement the IEB with 2 additional data sources. First we obtained information on direct interactions with caseworkers along three dimensions: invitations for person appointments at the local UI agency, on vacancy referrals and on integration contracts 11 Second, we also obtained data on the integration profile assignments by the caseworkers.

\footnotetext{
${ }^{10}$ In particular self-employment as well as some government jobs are not subject to social security contributions and not included in the data.

${ }^{11}$ More information on these variables is available in Hofmann and Köhler (2014).
} 
Table 1 reports summary statistics for the main characteristics of our sample. Column 1 shows the full sample of all UI claims of individuals aged 48 to 51 at the time of claiming, including individuals who have shorter eligibility durations which we do not use for our RD sample. Column 2 shows the sample restricted to individuals in our RD sample, that is individuals who have worked for at least 30 months in the preceding 5 years. We lose around 10 percent of the observations, but most characteristics remain very similar. The restricted sample is somewhat more positively selected with higher pre and post-unemployment wages. Columns 3 and 4 split up the analysis sample into individuals above and below the age cutoff. This reveals strong differences between the two age groups that, as we will show later, are driven by age gradients for most variables highlighting the importance of isolating the variation at the age discontinuity to obtain the causal effect of the change in UI eligibility. The individuals above the cutoff have longer unemployment durations, a smaller probability of finding a job within 18 months, and lower post-unemployment wages.

\section{Method}

\subsection{Empirical specification}

The main contribution of this paper is to provide estimates of whether caseworkers respond to differences in UI generosity across workers by allocating their resources differently. To do so we estimate variants of equation (3), with various measures of caseworker actions as outcome variables. The main empirical challenge when estimating equation (3) is that $\varepsilon_{i}$ will typically be correlated with $b_{i}$, for example since individuals with higher UI eligibility (in benefit levels or durations) typically come from more stable, high paying employment relationships. To avoid omitted variable bias, we therefore estimate the effect of UI generosity using a regression discontinuity design, exploiting the sharp age cutoff at age 50. For this we compare caseworker actions towards workers who claim UI benefits either shortly before or shortly after their 50th birthday while also controlling for trends in age. To implement 
this we estimate versions of the following equation:

$$
y_{i}=\beta+\delta \mathbf{1}\left(a_{i} \geq 50\right)+f\left(a_{i}\right)+\varepsilon_{i}
$$

where $y_{i}$ is an outcome for individual $i, a_{i}$ is the age of $i$ at the time of claiming UI benefits measured in days and $f($.$) is a function controlling for secular effect of age on the outcome.$ We estimate this equation locally around the cutoff using a linear spline specification for $f($. with different slopes on each side of the cutoff. The coefficient $\delta$ captures the extent to which caseworkers act differently toward the high-UI eligible unemployed older than 50 at the age of claiming. Since we are particularly interested in whether caseworker actions may lead to bias in estimating the disincentives effects of UI (as in equation 2), we also show that there is in fact a significant effect of UI generosity on unemployment durations at the age cutoff by estimating equation (4) with measures of job finding rates and unemployment durations as dependent variables.

As we will document below, unemployed workers above the age cutoff remain longer on UI benefits, partly due to the mechanical effect of increased UI eligibility and partly due to the behavioral effect of lower exit rates from unemployment when UI benefits increase. Since caseworkers only interact with the workers while (and before) they are receiving UI benefits, there is a mechanical effect leading to more caseworker interactions with the unemployed workers who claim benefits above the age cut-off. While we show some baseline results of caseworker behavior not correcting for this mechanical effect, for our main specification we adjust all caseworker variables to be comparable across the two groups. To do so we calculate the number of caseworker interactions within three months before and the first 12 months after claiming UI benefits (thus assuring that caseworker interactions are only measured over the timeframe when both groups of workers are eligible to UI) ${ }^{12}$. We then rescale these caseworker interactions within 12 months by dividing by the number of months a worker actually spends in UI benefits.

\footnotetext{
${ }^{12}$ We start three months before UI entry, since workers who know that their job will end are required to register for job search three months before job-loss.
} 
Adjusting the caseworker variables for the increase in UI durations on each side of the cutoff helps to isolate the caseworker response to UI eligibility from the mechanical effect that the duration of contact between the caseworker and the UI recipient is changing. However, looking at how mean caseworker variables are changing at the age discontinuity may hide important dynamic patterns. For example, one way how caseworkers might respond to potential UI durations is by concentrating extra resources on workers close to the exhaustion point to help these workers find a job before they run out of UI benefits. Similarly, caseworkers can help the unemployed close to the exhaustion point by prolong their duration on UI benefits through active labor market programs, during which individuals may receive benefits even after regular UI benefits are exhausted. We estimate how caseworker responses are changing throughout the UI spell using the following regression model:

$$
y_{i t}=\beta_{t}+\delta_{t} \mathbf{1}\left(a_{i} \geq 50\right)+f_{t}\left(a_{i}\right)+\varepsilon_{i t} \mid t_{i} \geq t
$$

$t_{i}$ is the month individual $i$ is exiting UI and we estimate this equation for each month $t$ when individuals are on UI $(t=1, \ldots, 12)$. Thus the sample in each regression are all individuals who are still in UI in month $t$. The outcome $y_{i t}$ are caseworker interactions of individual $i$ in month $t$ of the UI spell. Estimating equation (5) for each $t$ provides a vector of $\beta_{t}$ which represents the average caseworker interactions of individuals in month $t$ just to the left of the age discontinuity, while $\delta_{t}$ represents the discontinuous shift in the number of caseworker interactions in that month. Plotting $\delta_{t}$ and $\beta_{t}+\delta_{t}$ provides the level of interactions to the left and the right of the cutoff and the estimated standard errors on $\delta_{t}$ allow for a straightforward test of whether the levels of interactions change at the age discontinuity in each month.

\subsection{Validity of the RD design}

There are two main reason why the exclusion restriction may be violated in our situation.

First, workers might systematically delay claiming UI benefits in order to be eligible for the 
longer potential UI durations. For example a worker who is laid off 1 week before their 50th birthday could wait 1 week in order to be eligible for an additional 3 months of UI benefits. ${ }^{13}$ Second, there may be systematically higher inflows (and possibly of different types) at higher potential UI durations, e.g. because firms systematically are more likely to lay off workers with higher UI eligibility.

To test for these possible violations, we look at how the density of inflows as well as observable characteristics vary around the cutoff. Figure 1 (a) shows the number of inflows into UI in two-weeks age bins between age 45 and 55 for our sample. On average around 1000 workers claim UI benefits in each age window over our time period and there is a negative correalation with age. There is a small dip in the density just to the left of the age discontinuity and a little bit of extra mass just to the right. On the other hand there does not appear to be a permanent increase in the density at the age discontinuity. The dip/spike in the density suggests a small amount of claim delaying around the cutoff but only of about 200 people out of a sample of around 100,000 Observations in our 2 year age window around the cutoff. It is consistent with the incentives to delay UI benefits, that this should mainly occur very close to the cutoff (since for individuals further away from the cutoff delaying is very costly if they do not exhaust ui benefits).

The result suggests, that while there is some delayed claiming just at the threshold, there is no evidence for manipulation further away and in particular there do not seem to be systematic effects of being above the age cutoff on UI inflows. This conclusion is supported when looking at observable characteristics by age. Figure 1 (b) plots predicted pre-unemployment wages (where wages are predicted using a linear wage regression of preunemployment log wages on a large vector of observables) by age cells. There is no discernible difference at the cutoff, suggesting that the basic RD is valid. We exclude one month at each side of the cutoff in our baseline specification as a cautionary measure. In the robsutness section we show that our results are not sensitive to this decision. Table 2 shows for a large number of individual outcome variables whether they change at the age cutoff. Despite

\footnotetext{
${ }^{13}$ The incentives for delayed claiming were discussed in detail in Schmieder, von Wachter and Bender (2012), both in the main text and the online appendix.
} 
a large $\mathrm{N}$ and therefore a precise estimation, we find for all predetermined variables no significant differences in our baseline specification. After our main analysis we provide a large number of robustness checks to explore the importance of these assumptions further.

\section{Results}

\subsection{The disincentive effect of UI}

We begin by documenting the effect of an increase in potential UI eligibility on the duration of UI benefit receipt and nonemployment. Figure 2 a) shows the average UI benefit duration by age of claiming UI. There is a slight increase in UI durations by age and a clear discontinuous jump at the age 50 threshold, when UI eligibility increases from 12 to 15 months. At the discontinuity average duration of UI benefit receipt increases from around 6.6 to 7.6 months. This is confirmed in the RD regression in Table 3. Column (1) that shows an estimate of 0.95 months increase in UI duration at the threshold or about 0.32 months for each additional month of UI benefits. This increase is partly mechanical - due to the increased coverage and partly due to behavioral responses - since unemployed individuals exit unemployment slower. Figure $2 \mathrm{~b}$ ) shows how nonemployment duration varies at the age threshold, a purely behavioral response. Since our data only covers observations until the end of 2011, we topcode all nonemployment duration spells at 18 months ${ }^{14}$ Nonepmployment also shows a clear increase at the threshold of around 0.2 months, which is confirmed in Table 3 , Column (2). Column (3) shows that the probability of finding a job within 18 months after the start of the UI spell is also reduced by about 1.3 percent. Overall the increase in potential UI durations at the age 50 threshold has a clear statistically significant effect on unemployment durations. The magnitude of the coefficient estimate for UI benefit duration is very similar to the results that Schmieder et al. (2012a) found for the earlier age cutoffs in the 1980s to early 2000s. The point estimates for unemployment duration are not quite comparable due

\footnotetext{
${ }^{14}$ Based on our work on other age cutoffs, topcoding at such a relatively low value will underestimate the effect on nonemployment durations, which is why we also show results on the probability of finding a job within 18 months. Furthermore we report below how the hazard and survivor functions change at the age cutoff, which are both unaffected by the censoring.
} 
to the shorter top-coding but in a similar ballpark.

Figure 3 a) shows how the hazard function of leaving unemployment changes at the age threshold. The figure is based on estimating equation (5) pointwise with an indicator for exiting in a given period $t$ conditional on still being unemployed at period $t$. The figure shows that there is a clear spike in the hazard rate in the month when UI benefits expire. The difference is large and clearly significant in the months of benefit expiration (that is in the first month after benefits are cut), as well as in some of the month before or after the exhaustion point. The hazard rate for individuals with 12 months of eligibility is also somewhat larger in the months leading up to month 12 , but except for month 11 not statistically significantly different. ${ }^{15}$ Figure $3 \mathrm{~b}$ ) graphs the corresponding survivor function. As suggested by the hazard rate, the survivor functions start to diverge 1 month before benefit exhaustion for the 12 month group and remain different for the remaining period (though they converge again after month 15). The fact that the survivor functions are different even before month 12 highlights the importance of rescaling the number of caseworker interactions by the actual time spent on UI benefits. Note that we see essentially no difference in the survivor functions early on in the UI spell, which is why we also report results on caseworkers' interactions within the first 4 months of entering UI in the next subsection.

The results show that the UI extensions are important in practice: individuals above the threshold benefit significantly from the expanded UI duration and they remain unemployed longer. This suggests that if caseworkers take UI eligibility into account through any of the dimensions discussed in section 2, then we should observe differences in caseworker actions around the age threshold.

\subsection{The effect of UI eligibility on caseworker interactions}

Next we turn to our main results on how caseworker actions change at the age discontinuity.

Table 4 presents estimates on how caseworkers adjust job-search assistance due to an

\footnotetext{
${ }^{15}$ Analysis of the earlier age cutoffs in Schmieder et al. (2012a) suggest that the fact that the difference in hazard rates is not statistically significant until month 11 is likely due to the small sample size here and that hazard rates are indeed higher for the shorter eligibility group for most of the UI spell.
} 
increase in potential UI duration measured in number of invitations, number of signed contracts and number of job referrals. In the first row, the total number of assistance received during the first 12 months since UI entry for each of these caseworker measures are used as outcome variables. RD estimates show a significant increase of between $3 \%$ and $5 \%$ in the total number of caseworker contacts. However, this does not account for the fact that worker with longer potential UI receipt are more likely to be unemployed towards the end of the 12 month period and thus mechanically have more contact with caseworkers. We therefore construct as outcome variables the number of case worker contacts a worker receives per months of UI receipt, by dividing the number of contacts by the actual time spent on UI benefits. Row two and three show RD estimates for the constructed intensity measures within the first twelve and first four months of UI receipt. In all cases the point estimates of the intensity specification are close to zero and -with some exception for number of contractsinsignificant on any common significance level. Furthermore, the coefficients are precisely estimated ruling out sizable responses of caseworkers to an increase in potential UI duration. The corresponding RD-plots in Figures 4 a)-c) -while exhibiting a continuous decline of caseworker's support with age- show no jump at the relevant age cutoff, underscoring that caseworker do not respond their assistance with regard to potential UI duration. This finding is robust with respect to several robustness checks performed in the next section.

As an indirect way of whether caseworkers may interact differently with the unemployed who are older than age 50 we can explore the assignment into different labor market profiles that occurs at the beginning of an UI spell. We begin by collapsing the different labor market profiles to a single index corresponding to the ordering of the profile (the profile that corresponds to workers with the highest expected job finding probability receives a value of 1 and the profile with the lowest a value of 4). Figure 4 d) shows how the profile assignment varies by age and that older workers are systematically assigned to profiles that correspond to lower expected job finding probabilities. Furthermore there is a small jump around age 50 , where the average profile index increases from around 2.2 to 2.3 . It is noteworthy that profile assignment may occur before or after an individual actually claims UI benefits (it 
can happen when the worker first registers for job search for example which may be several months prior to the start of UI). This is also supported by Table 5 which shows the probability of assignment to the individual profiles. As Figure 4 d) shows, the profile index does not jump exactly at age 50, but rather shows a rapid increase from a few months before to a few months after the age 50 cut-off. This suggests, that it may not actually be related to an increase in UI benefits but rather a form of age discrimination where age 50 is a salient number and caseworkers may believe it harder for workers above that age cutoff to find jobs. Of course this could also reflect age discrimination by potential employers who may be biased against hiring workers older than age 50. Furthermore, it is important to note that even in the presence of age discrimination, the validity of the RD design should not be affected, which is only based on the age at claiming UI benefits. Since we are comparing workers who claim benefits shortly before or after their 50th birthday, both groups will be age 50 for most of their UI spell and in particular when they get closer to the exhaustion point of UI benefits, thus even if employers discriminate against workers older than age 50 it would not have a differential effect on the treatment and control group in this design. ${ }^{16}$ The differences in profiles could however affect the actions of the caseworker throughout the spell if the initial assessment affects the integration strategy of the caseworkers. Given that we do not observe any significant differences this seems unlikely however.

\subsection{The effect of UI eligibility on active labor market program participation}

Next we turn to assignments to active labor market programs. Figure 5 shows for a variety of measures of active labor market programs, how the average time of program participation (per month of being on UI) varies by the age of claiming UI benefits. The figure shows that there are no discontinuities at the age cutoffs in any of the measures. For example an unemployed person spends around 1.4 days per month of UI receipt in a training program, but this does not vary at the age cutoff. This is also confirmed in Table 6 which shows no economically or statistically significant differences at the age cutoff. Thus it does not

\footnotetext{
${ }^{16}$ Consistent with this, in section 5.5 we provide a placebo test, where we find no increase in nonemployment duration at age 50 in a time period where there was no UI discontinuity at that age threshold.
} 
appear that caseworkers compensate for the differences in UI eligibility by targetting ALMP resources differently to workers with different UI eligibility.

\subsection{Dynamic effects of UI extensions on caseworker interactions}

Up to now, we have looked at crossectional estimates. To examine caseworkers' response over the spell of UI benefit receipt, we perform dynamic estimates based on equation (5) for our three main caseworker variables. Figure 6 a)-c) shows how caseworker contacts in the form of vacancy referrals, invitations to the UI agency and integration contracts change throughout the unemployment spell as well as at the age discontinuity. Most integration contracts (a) are signed right at the beginning of the UI spell, with some occurring prior to that (presumably at the time when individuals register for job search) or shortly afterwards. There are new intergration contracts (or likely rather updates to the existing contracts) later during the UI spell at a frequency of about 1 every 4 months. Turning to invitations of the unemployed to the UI agency, we see that close to 40 percent of the unemployed receive an invitation just prior to starting on UI benefits and an additional 50 percent during the first month of UI benefits. Afterwards invitations continue at a pace of about one in every three months. A very similar patter can be observed for vacancy referrals with a spike early on in the UI spell and then about one referral every three months. Regarding the differences at the age discontinuity, we observe only small and mostly insignificant differences between the 12 and 15 months of eligibility duration for all months of UI receipt. The small differences present do not seem to increase or decrease over the spell of UI receipt. Importantly, caseworker seem not to increase or decrease their assistance when approaching the exhaustion point. Thus, caseworker behavior can not contribute to explaining higher reemployment hazard around UI exhaustion (the so called "spike at the exhaustion point") which is visible in Figure 3 .

Figure 6d) shows the number of days spent in education or vocational training programs. Here we see a significant increase during early part of the UI spell, with a maximum around 4 months after the start of receiving UI benefits. Interestingly there is a gap in time spent in education programs in the 4 months prior to the exhaustion point with individuals with 
12 months of potential UI benefits being more likely to participate in such a program. Participation in a training program effectively allows for an extension of UI benefits, since an individual continues to receive UI benefits while in a program (even if regular benefits are already exhausted) and if benefits are not yet exhausted, each day in a training program only uses up half a day of UI eligibility. Furthermore if an individual finishes a training program he can always receive UI benefits for the remainder of the calendar month. This may create an incentive for the unemployed to participate in training programs close to the UI exhaustion point or for the caseworker to allocate slots in training programs to workers who otherwise might lose UI benefit soon. While we cannot disentangle whether this is due to the caseworker shifting resources or due to the unemployed seeking out training programs, overall the effect is quite small (as can be seen from the fact that the crossectional effects are close to zero). Furthermore it seems likely that participation in training programs decreases job finding probabilities at least in the short run, since workers are likely not looking for jobs while in the program and have fewer incentives to find a job right away. Thus this would go in the opposite direction of the disincentive effect of UI benefits and in turn this dimension of caseworker action could not account for the observed disincentive effect of UI. Figure 6 e) shows similarly that there are no differences for participation in private job placement services.

In Figure 6f) we show the sanctioning probability throughout the UI spell. Sanctions are most likely right at the beginning, likely due to voluntary quits or failure to register for job search in time. Afterwards they are relatively rare and declining over the UI spell, with around 0.5 days of sanctioned UI benefit days per month and no differences across the two groups. Thus it does not seem that caseworkers attempt to counteract the disincentive effects of UI benefits through increased sanctioning of the workers with higher eligibility.

\subsection{Robustness}

To check the validity of our estimates, we perform several robustness checks for our main results that are summarized in Table 7. To check for potential (functional) misspecification 
in age, we vary the length of bandwidth and include quadratic age polynomials separately on each side of the cutoff. As an additional test for the random assignment assumption, a rich set of control variables is included in a next specification. Controls are the daily pre-unemployment wage, dummies for nationality, gender, children, marital status, east Germany and six educational groups, the duration till take-up, actual experience, occupational-, industry- and establishment tenure as well as seasonal (monthly) controls. Further checks use bias adjusted estimates with robust standard errors as proposed by Calonico et al. (2014) and asses the sensitivity of not excluding values within one months at each side of the cutoff.

Finally, a placebo test at the age threshold 50 for the years 2006 and 2007 examines the influence on outcome variables when potential UI duration stays constant on both sides of the threshold.

For all specifications during the period with real treatment, the effect on duration of UI benefits receipt as well as on nonemployment are positve and -except for the smaller sample size in the half binsize specification- significant on the $5 \%$ significance level. The point estimates for the placebo specification during the years 2006 and 2007 are in contrast insignificant and close to zero, ruling out signaling effects at the age threshold 50. Overall, the robustness checks confirm the finding of a higher nonemployment duration due to UI extension.

The estimates on caseworker actions are in contrast insignificant and close to zero for all specifications with some exceptions of training programs and the assigned labor market profile at UI entry. For the main caseworker actions (invitation to meetings as well as provided vacancy referrals) the precision of the estimates rules out caseworker reactions of considerable size.

\section{Conclusion}

Caseworkers play a major role in modern unemployment insurance systems where they are tasked with both supporting and monitoring the recipients of UI benefits. Many countries spend large amounts on caseworkers and provide them with many resources to facilitate 
faster transitions of the unemployed back into work. Despite this, relatively little is know about the motivations of caseworkers and how they may respond to institutional features such as the structure of UI benefits. This paper investigates one aspect of caseworker actions, namely whether they respond to differences in UI eligibility across the unemployed. Our results suggest that caseworkers do not seem to significantly change their behavior at the age discontinuity determining UI eligibility, which may be a bit surprising given that there are many possible motivations that would lead to caseworkers adjusting their behavior as discussed in Section 2. In particular it does not appear to be the case that caseworkers shift resources to help the disadvantaged unemployed with shorter UI durations, or to counteract the disincentive effects of UI. This holds for a wide variety of measures of caseworker actions and appears quite robust. Our findings are thus consistent with the stylized model of the bureaucratic caseworker laid out in framework section, where caseworkers follow either explicit or implicit guidelines regarding how to interact with the unemployed in a way that is not responsive to the difference in UI generosity or the different search behavior induced by it. Alternatively the findings would also be consistent with a lack of awareness of salience of the differences in UI eligibility.

At least in this context it does not seem that caseworkers are using their resources to minimize unemployment durations or to maximize welfare of the unemployed in a utilitarian sense. It should of course be noted that our zero result could mask heterogeneous responses that cancel each other out, but at least on average it does not appear that there is a systematic response by caseworkers to differences in UI eligibility. A positive implication of this finding from a research perspective is that the typical estimates of the disincentive effects of UI are not confounded by endogenous caseworker actions. 


\section{References}

Abbring, Jaap H., Gerard J. van den Berg, and Jan C. van Ours, "The Effect of Unemployment Insurance Sanctions on the Transition Rate from Unemployment to Employment," The Economic Journal, 115 (505), (2005), 602-630.

Bell, Stephen H and Larry L Orr, "Screening (and creaming?) applicants to job training programs: the AFDC homemaker-home health aide demonstrations," Labour Economics, 9 (2), (2002), 279 - 301. Evaluation of Active Labour Market Policies.

Black, D, J Smith, M Berger, and B Noel, "Is the threat of training more effective than training itself? Evidence from random assignments in the UI system," American Economic Review, 93 (4), (2003), 1313-1327.

Boockmann, Bernhard, Christopher Osiander, Michael Stops, and Hans Verbeek, "Effekte von Vermittlerhandeln und Vermittlerstrategien im SGB II und SGB III (Pilotstudie): Abschlussbericht an das IAB durch das Institut für Angewandte Wirtschaftsforschung e. V.(IAW)," Technical Report, IAB-Forschungsbericht (2013).

Calonico, Sebastian, Matias D. Cattaneo, and Rocio Titiunik, "Robust Nonparametric Confidence Intervals for Regression-Discontinuity Designs," Econometrica, 82 (6), (2014), 22952326 .

Card, David, Andrew Johnston, Pauline Leung, Alexandre Mas, and Zhuan Pei, "The Effect of Unemployment Benefits on the Duration of Unemployment Insurance Receipt: New Evidence from a Regression Kink Design in Missouri, 2003-2013," American Economic Review, 105 (5), (2015), 126-30.

_ , David S Lee, Zhuan Pei, and Andrea Weber, "Inference on Causal Effects in a Generalized Regression Kink Design," Econometrica, (forthcoming).

_ , Jochen Kluve, and Andrea Weber, "Active Labour Market Policy Evaluations: A MetaAnalysis," The Economic Journal, 120 (548), (2010), F452-F477.

_, _, and _, "What works? A meta analysis of recent active labor market program evaluations," Technical Report, National Bureau of Economic Research (2015).

_, Raj Chetty, and Andrea Weber, "Cash-On-Hand and Competing Models of Intertemporal Behavior: New Evidence from the Labor Market," Quarterly Journal of Economics, 122 (4), (2007a), 1511-1560.

Chetty, Raj, "Moral Hazard versus Liquidity and Optimal Unemployment Insurance," Journal of Political Economy, 116 (2), (2008), 173-234.

Eichhorst, Werner and Paul Marx, "Reforming German labour market institutions: A dual path to flexibility," Journal of European Social Policy, 21 (1), (2011), 73-87. 
Giulietti, Corrado, Annette Bergemann, Marco Caliendo, Gerard J van den Berg, and Klaus F Zimmermann, "The threat effect of participation in active labor market programs on job search behavior of migrants in Germany," International journal of manpower, 32 (7), (2011), 777-795.

Heckman, James, Carolyn Heinrich, and Jeffrey Smith, "Assessing the Performance of Performance Standards in Public Bureaucracies," The American Economic Review, 87 (2), (1997), pp. 389-395.

Hofmann, Barbara, "Short-and Long-term Ex-Post Effects of Unemployment Insurance Sanctions: Evidence from West Germany," Jahrbücher für Nationalökonomie und Statistik, (2012), 31-60.

- and Markus Köhler, "New register data from the German public employment service on counseling and monitoring the unemployed," Schmollers Jahrbuch, 134 (09), (2014), 129-140.

Johnston, Andrew and Alexandre Mas, "Potential Unemployment Insurance Duration and Labor Supply: The Individual and Market-Level Response to a Benefit Cut," Technical Report, working paper (2015).

Lalive, Rafael, "How do extended benefits affect unemployment duration? A regression discontinuity approach," Journal of Econometrics, 142 (2), (2008), 785-806.

_ , Jan C van Ours, and Josef Zweimüller, "The effect of benefit sanctions on the duration of unemployment," Journal of the European Economic Association, 3 (6), (2005), 1386-1417.

_, Jan van Ours, and Josef Zweimüller, "How Changes in Financial Incentives Affect the Duration of Unemployment," Review of Economic Studies, 73 (4), (2006), 1009-1038.

Landais, Camille, "Assessing the welfare effects of unemployment benefits using the regression kink design," American Economic Journal: Economic Policy, (forthcoming).

Meyer, Bruce D., "Unemployment Duration and Unemployment Spells," Econometrica, 58 (1990), 757-82.

Moffitt, Robert, "Unemployment Insurance and the Distribution of Unemployment Spells," Journal of Econometrics, 28 (1), (1985), 85-101.

Schmieder, Johannes F and Till von Wachter, "Effects of Unemployment Insurance: New Evidence and Interpretation," Technical Report (2015).

Schmieder, Johannes F., Till von Wachter, and Stefan Bender, "The Effects of Extended Unemployment Insurance over the Business Cycle: Evidence from Regression Discontinuity Estimates over 20 years," The Quarterly Journal of Economics, 127 (2), (2012a), 701-752.

Schmieder, Johannes F, Till von Wachter, and Stefan Bender, "The Long-Term Effects of UI Extensions on Employment," The American Economic Review, 102 (3), (2012b), 514-519. 
_, _, and _, "The Effect of Unemployment Benefits and Nonemployment Durations on Wages," The American Economic Review, (forthcoming).

Schütz, Holger, Peter Kupka, Susanne Koch, and Bruno Kaltenborn, "Eingliederungsvereinbarungen in der Praxis: Reformziele noch nicht erreicht," IAB-Kurzbericht, 18 (2011), 2011.

Student, "The Lanarkshire milk experiment," Biometrika, (1931), 398-406.

Svarer, Michael, "The effect of sanctions on the job finding rate: evidence from Denmark," (2007).

van den Berg, Gerard J., Bas van der Klaauw, and Jan C. van Ours, "Punitive Sanctions and the Transition Rate from Welfare to Work," Journal of Labor Economics, 22 (1), (2004), pp. 211-241. 
Table 1: Summary Statistics of UI Spells Age 48-51 from April 2008 - June 2010

\begin{tabular}{|c|c|c|c|c|}
\hline & $\begin{array}{c}(1) \\
\text { Full } \\
\text { Sample* }\end{array}$ & $\begin{array}{c}(2) \\
\text { Eligigible } \\
\text { for Max UI** }\end{array}$ & $\begin{array}{c}(3) \\
\text { Age } 48 / 49 \\
\text { and Eligible }\end{array}$ & $\begin{array}{c}(4) \\
\text { Age } 50 / 51 \\
\text { and Eligible }\end{array}$ \\
\hline \multicolumn{5}{|l|}{ Individual Characteristics } \\
\hline \multirow[t]{2}{*}{ Female } & 0.48 & 0.48 & 0.47 & 0.47 \\
\hline & $\begin{array}{l}{[0.50]} \\
0.091\end{array}$ & $\begin{array}{l}{[0.50]} \\
0.076\end{array}$ & {$[0.50]$} & {$[0.50]$} \\
\hline Non-German & {$[0.29]$} & {$[0.26]$} & {$[0.27]$} & {$[0.26]$} \\
\hline \multirow[t]{2}{*}{ West Germany } & 0.82 & 0.82 & 0.82 & 0.82 \\
\hline & {$[0.38]$} & {$[0.38]$} & {$[0.39]$} & {$[0.38]$} \\
\hline \multirow[t]{2}{*}{ Age } & 49.9 & 50.0 & 49.0 & 51.0 \\
\hline & [1.15] & [1.15] & {$[0.57]$} & {$[0.58]$} \\
\hline \multirow[t]{2}{*}{ Education years } & 11.1 & 11.2 & 11.2 & 11.2 \\
\hline & {$[2.57]$} & {$[2.62]$} & {$[2.64]$} & {$[2.60]$} \\
\hline \multicolumn{5}{|l|}{ Unemployment and UI Duration } \\
\hline \multirow{2}{*}{ Nonemployment Duration in months (cap 36 Months) } & 19.3 & 18.4 & 17.7 & 19.2 \\
\hline & {$\left[\begin{array}{l}15.1 \\
11.5\end{array}\right]$} & {$[15.0]$} & $\begin{array}{c}{[14.9]} \\
10.8\end{array}$ & {$[15.0]$} \\
\hline Nonemployment duration capped at 18 months & {$[6.95]$} & {$[6.96]$} & {$[6.96]$} & {$[6.94]$} \\
\hline \multirow[t]{2}{*}{ Duration of ALG receipt (net) } & 7.00 & 7.09 & 6.45 & 7.77 \\
\hline & {$[5.35]$} & {$[5.48]$} & {$[4.96]$} & {$[5.89]$} \\
\hline \multicolumn{5}{|l|}{ Pre- and Post UI Characteristics } \\
\hline \multirow[t]{2}{*}{ Next Wage after UE } & 52.5 & 54.7 & 55.0 & 54.4 \\
\hline & {$[31.1]$} & {$[31.8]$} & {$[32.2]$} & {$[31.4]$} \\
\hline \multirow[t]{2}{*}{ Last Wage prior to UE } & 64.4 & 68.7 & $68.8^{1}$ & 68.6 \\
\hline & {$[39.0]$} & {$[38.8]$} & {$[38.9]$} & {$[38.6]$} \\
\hline \multirow[t]{2}{*}{ Maximum UI Duration (imputed) } & 12.6 & 13.5 & 12.0 & 15 \\
\hline & {$[2.97]$} & {$[1.50]$} & [0.083] & {$[0]$} \\
\hline \multirow[t]{2}{*}{ Probability of leaving unemp. within first 18 months } & 0.54 & 0.57 & 0.59 & 0.54 \\
\hline & {$[0.50]$} & {$[0.50]$} & {$[0.49]$} & {$[0.50]$} \\
\hline \multicolumn{5}{|l|}{ Invitations and Referrals } \\
\hline Number of Invitations per Month of UI receipt & 0.32 & 0.33 & 0.33 & 0.33 \\
\hline Number of Contracts per Month of UI receipt & 0.22 & 0.24 & 0.24 & 0.24 \\
\hline Number of Referrals per Month of UI receipt & 0.23 & 0.25 & 0.26 & 0.25 \\
\hline \multicolumn{5}{|l|}{ Profile Assignment } \\
\hline Market profile at beginning of UI spell & 0.14 & 0.16 & 0.18 & 0.14 \\
\hline Activation profile at beginning of UI spell & 0.095 & 0.011 & 0.12 & 0.098 \\
\hline Support profile at beginning of UI spell & 0.22 & 0.24 & 0.21 & 0.27 \\
\hline Development profile at beginning of UI spell & 0.026 & 0.023 & 0.019 & 0.026 \\
\hline \multicolumn{5}{|l|}{ Measures } \\
\hline Number of days in measures when recieving UI & 19.8 & 21.3 & 20.9 & 21.7 \\
\hline Number of days in flexible labor market programms when on UI & 1.03 & 0.95 & 0.88 & 1.02 \\
\hline Number of days training programms when on UI & 13.7 & 15.1 & 15.6 & 14.6 \\
\hline Number of days in placement services when on UI & 4.55 & 4.76 & 4.01 & 5.55 \\
\hline Number of days receiving wage subsidy when on UI & 0.024 & 0.0048 & 0.0077 & 0.0018 \\
\hline Number of days in public employment programms when on UI & 0.51 & 0.42 & 0.38 & 0.46 \\
\hline At least one day selfemployed when receiving UI & 0.0095 & 0.0097 & 0.0096 & 0.0098 \\
\hline \multirow{2}{*}{ Sanctioned at the beginning of UI entry } & 0.20 & 0.21 & 0.21 & 0.21 \\
\hline & {$[0.40]$} & {$[0.41]$} & {$[0.41]$} & {$[0.41]$} \\
\hline Number of observations & 138288 & 102809 & 52710 & 50099 \\
\hline
\end{tabular}

Notes: This Table summarizes the IEB-caseworker data for UI entries between 04/2008-06/2010. *Individuals between age 48 and 51 . **Individuals between age 48 and 51 who are eligible for UI benefits for at least 12 Month, have worked at least 3 years during the last 5 years and took up UI benefits within 3 months after job-loss. Note the formatting of the standard deviations and the omission of the SD for binary variables. 
Table 2: Validity Test of the Regression Discontinuity Design: Smoothness of Predetermined Characteristics

\begin{tabular}{lcccccc}
\hline & $\begin{array}{c}\text { Years of } \\
\text { Education }\end{array}$ & Female & $\begin{array}{c}\text { Foreign } \\
\text { Citizen }\end{array}$ & $\begin{array}{c}\text { Tenure } \\
\text { Last Job }\end{array}$ & $\begin{array}{c}\text { Exp. } \\
\text { Last Job }\end{array}$ & $\begin{array}{c}\text { Pre } \\
\text { Wage }\end{array}$ \\
D(Age above Cutoff) & 0.0023 & -0.0050 & -0.0045 & 0.040 & 0.17 & 0.61 \\
& {$[0.034]$} & {$[0.0066]$} & {$[0.0035]$} & {$[0.096]$} & {$[0.12]$} & {$[0.55]$} \\
Effect relative to mean & 0.00021 & -0.011 & -0.060 & 0.0064 & 0.0099 & 0.0088 \\
Observations & 98405 & 98405 & 98405 & 98405 & 98405 & 90523 \\
Mean of Dep. Var. & 11.2 & 0.47 & 0.076 & 6.29 & 16.8 & 68.6 \\
\hline & Time til & Occ Ten. & Ind Ten. & West & Children & Married \\
& Claim & Last Job & Last Job & Germany & $($ Dummy) & $($ Dummy) \\
& & & & & & \\
D(Age above Cutoff) & -0.0053 & 0.14 & 0.12 & 0.0023 & -0.0032 & -0.0017 \\
& {$[0.0052]$} & {$[0.12]$} & {$[0.099]$} & {$[0.0052]$} & {$[0.0065]$} & {$[0.0064]$} \\
Effect relative to mean & -0.039 & 0.011 & 0.0093 & 0.0028 & -0.0083 & -0.0027 \\
Observations & 98405 & 98405 & 98405 & 98405 & 98405 & 98405 \\
Mean of Dep. Var. & 0.13 & 12.6 & 13.3 & 0.82 & 0.38 & 0.64 \\
\hline
\end{tabular}

Notes: Coefficients from RD regressions. Each coefficient is estimated in a separate regression discontinuity model that controls linearly for age with different slopes and bandwidth of two age years on each side of cutoff. UI entries between $04 / 2008-06 / 2010$, one month at each side of the cutoff is excluded. Standard errors clustered on day level $\left.\left(+\mathrm{P}<.1,{ }^{*} \mathrm{P}<.05,{ }^{* *} \mathrm{P}<.01\right)\right)$.

Table 3: The Effect of Potential UI Durations on UI and nonemployment duration

\begin{tabular}{lccc}
\hline & $(1)$ & $(2)$ & $(3)$ \\
& $\begin{array}{c}\text { Unemp Ins. } \\
\text { Benefit } \\
\text { Duration }\end{array}$ & $\begin{array}{c}\text { Non-Emp } \\
\text { Duration } \\
18 \text { Months }\end{array}$ & $\begin{array}{c}\text { Exit } \\
\text { Prob } \\
18 \text { Mon }\end{array}$ \\
\hline D(Age above Cutoff $)$ & 0.95 & 0.17 & -0.013 \\
& {$[0.072]^{* *}$} & {$[0.089]+$} & {$[0.0065]^{*}$} \\
$\frac{d y}{d P}$ & 0.32 & 0.056 & -0.0043 \\
& {$[0.024]^{* *}$} & {$[0.030]+$} & {$[0.0022]^{*}$} \\
Effect relative to mean & 0.13 & 0.015 & -0.023 \\
Observations & 98405 & 98405 & 98405 \\
Mean of Dep. Var. & 7.08 & 11.2 & 0.57 \\
\hline
\end{tabular}

Notes: Coefficients from RD regressions. Each coefficient is estimated in a separate regression discontinuity model that controls linearly for age with different slopes and bandwidth of two age years on each side of cutoff. UI entries between 04/2008-06/2010, one month at each side of the cutoff is excluded. Standard errors clustered on day level $(+\mathrm{P}<.1, * \mathrm{P}<.05, * * \mathrm{P}<.01))$. 
Table 4: The Effect of Potential UI Durations on Caseworkers Job Search Assistance

\begin{tabular}{lccc}
\hline & $\begin{array}{c}(1) \\
\text { Number of } \\
\text { Invitations }\end{array}$ & $\begin{array}{c}(2) \\
\text { Number of } \\
\text { Signed Contracts }\end{array}$ & $\begin{array}{c}(3) \\
\text { Number of } \\
\text { Job referrals }\end{array}$ \\
\hline Total number of caseworker contacts & & \\
D(Age above Cutoff $)$ & 0.11 & 0.11 & 0.13 \\
& {$[0.035]^{* *}$} & {$[0.026]^{* *}$} & {$[0.051]^{*}$} \\
Effect relative to mean & 0.034 & 0.048 & 0.052 \\
Observations & 98405 & 98405 & 98405 \\
Mean of Dep. Var. & 3.25 & 2.33 & 2.42 \\
\hline Average number of contacts per months while on UI during first 12 months \\
D(Age above Cutoff) & 0.0021 & 0.0036 & 0.0019 \\
& {$[0.0029]$} & {$[0.0021]+$} & {$[0.0052]$} \\
Effect relative to mean & 0.0064 & 0.015 & 0.0073 \\
Observations & 98405 & 98405 & 98405 \\
Mean of Dep. Var. & 0.33 & 0.24 & 0.25 \\
\hline
\end{tabular}

Average number of contacts per months while on UI during first 4 months

$\begin{array}{lccc}\mathrm{D}(\text { Age above Cutoff }) & 0.0045 & 0.0046 & -0.0048 \\ & {[0.0031]} & {[0.0023]^{*}} & {[0.0053]}\end{array}$

$\begin{array}{llll}\text { Effect relative to mean } & 0.014 & 0.019 & -0.020\end{array}$

$\begin{array}{llll}\text { Observations } & 98405 & 98405 & 98405\end{array}$

Mean of Dep. Var. $\quad 0.33 \quad 0.24 \quad 0.23$

Notes: Coefficients from RD regressions. Each coefficient is estimated in a separate regression discontinuity model that controls linearly for age with different slopes and bandwidth of two age years on each side of cutoff. UI entries between $04 / 2008-06 / 2010$, one month at each side of the cutoff is excluded. Standard errors clustered on day level $\left.\left(+\mathrm{P}<.1,{ }^{*} \mathrm{P}<.05,{ }^{* *} \mathrm{P}<.01\right)\right)$. 
Table 5: The Effect of Potential UI Durations on Labor Market Profile Assignments

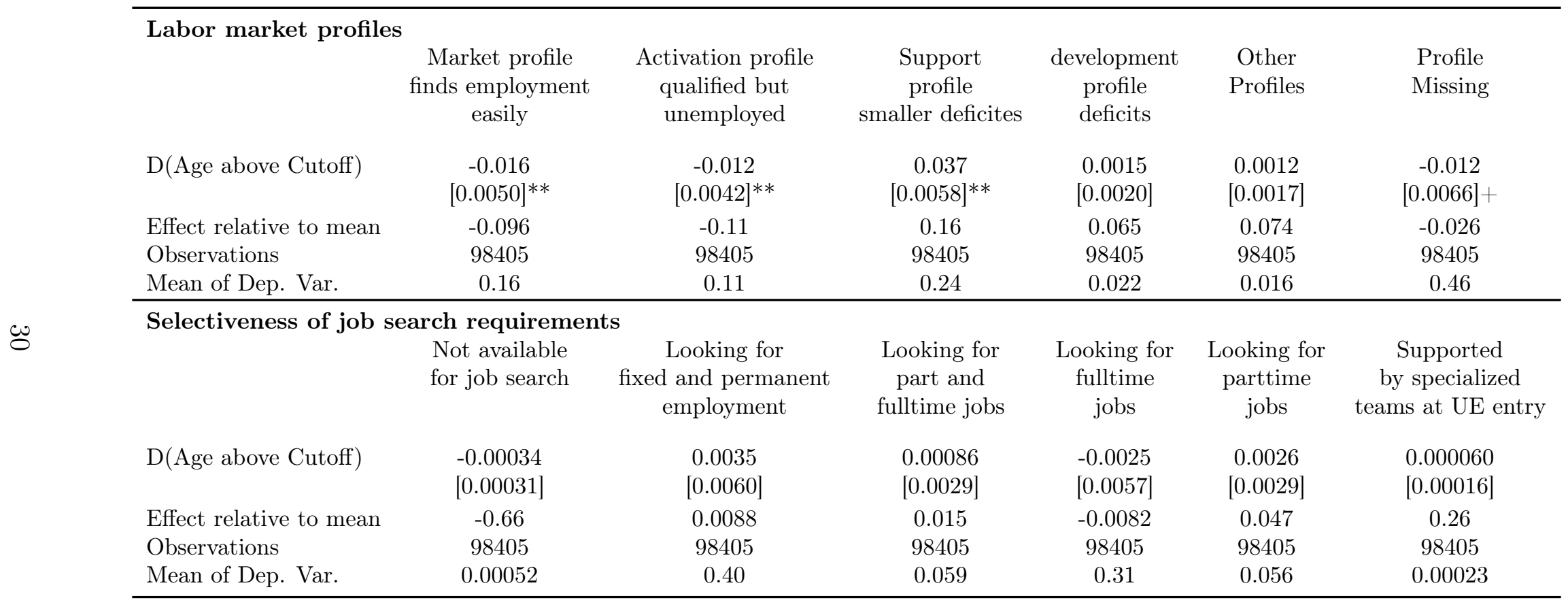

Notes: Coefficients from RD regressions. Each coefficient is estimated in a separate regression discontinuity model that controls linearly for age with different slopes and bandwidth of two age years on each side of cutoff. UI entries between 04/2008-06/2010, one month at each side of the cutoff is excluded. Standard errors clustered on day level $\left(+\mathrm{P}<.1,{ }^{*} \mathrm{P}<.05,{ }^{* *} \mathrm{P}<.01\right)$. 
Table 6: The Effect of Potential UI Durations on participation in Active Labor Market Programs (ALMPs)

\begin{tabular}{lccccc}
\hline & $\begin{array}{c}(1) \\
\text { Days in flexible } \\
\text { labor market } \\
\text { programs }\end{array}$ & $\begin{array}{c}(2) \\
\text { Days in public } \\
\text { employment } \\
\text { programs }\end{array}$ & $\begin{array}{c}(3) \\
\text { Days in } \\
\text { training } \\
\text { programs }\end{array}$ & $\begin{array}{c}(4) \\
\text { Days reciving } \\
\text { wage subsidies } \\
\text { when on UI }\end{array}$ & $\begin{array}{c}\text { Fraction } \\
\text { of sanctions } \\
\text { at UI entry }\end{array}$ \\
\hline Increase in Potential UI Dur. from 12 to & 15 Months & & & \\
D(Age above Cutoff) & 0.015 & 0.0064 & -0.069 & 0.00041 & -0.0032 \\
Effect relative to mean & {$[0.017]$} & {$[0.0096]$} & {$[0.044]$} & {$[0.0012]$} & {$[0.0055]$} \\
Observations & 0.15 & 0.20 & -0.055 & 0.86 & -0.015 \\
Mean of Dep. Var. & 98405 & 98405 & 98405 & 98405 & 98405 \\
\hline
\end{tabular}

Notes: Coefficients from RD regressions. Each coefficient is estimated in a separate regression discontinuity model that controls linearly for age with different slopes and bandwidth of two age years on each side of cutoff. UI entries between $04 / 2008-06 / 2010$, one month at each side of the cutoff is excluded. Standard errors clustered on day level $\left.\left(+\mathrm{P}<.1,{ }^{*} \mathrm{P}<.05,{ }^{* *} \mathrm{P}<.01\right)\right)$. 
Table 7: Sensitivity Analysis

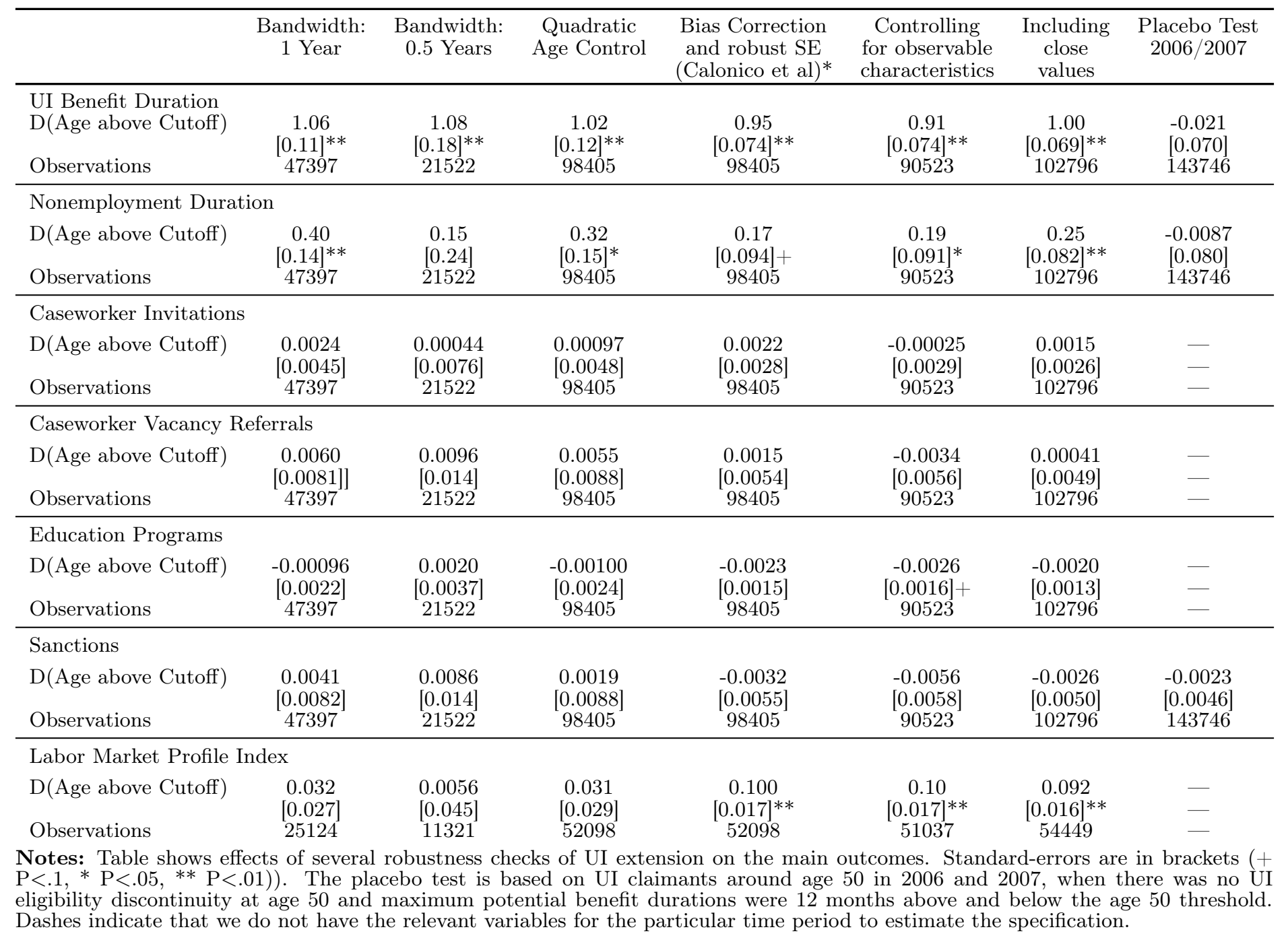


Figure 1: Density of UI Spells around Age Cutoff for Potential UI Duration

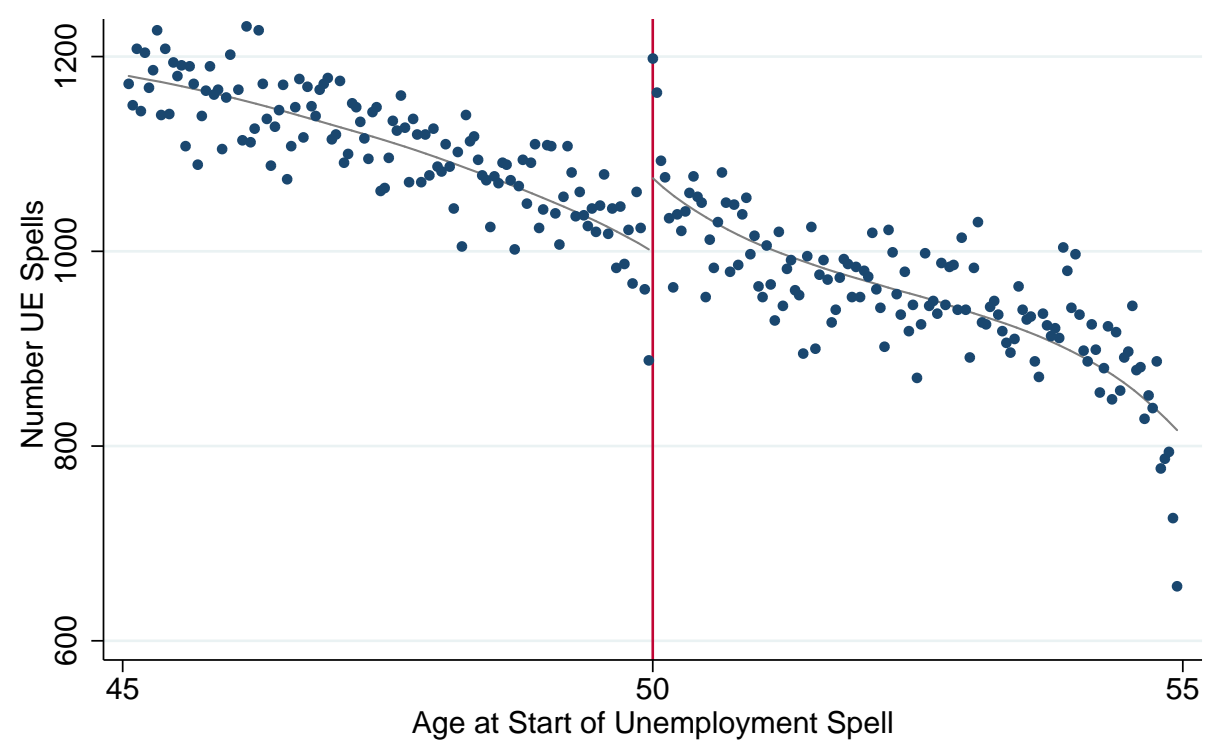

(a) Density

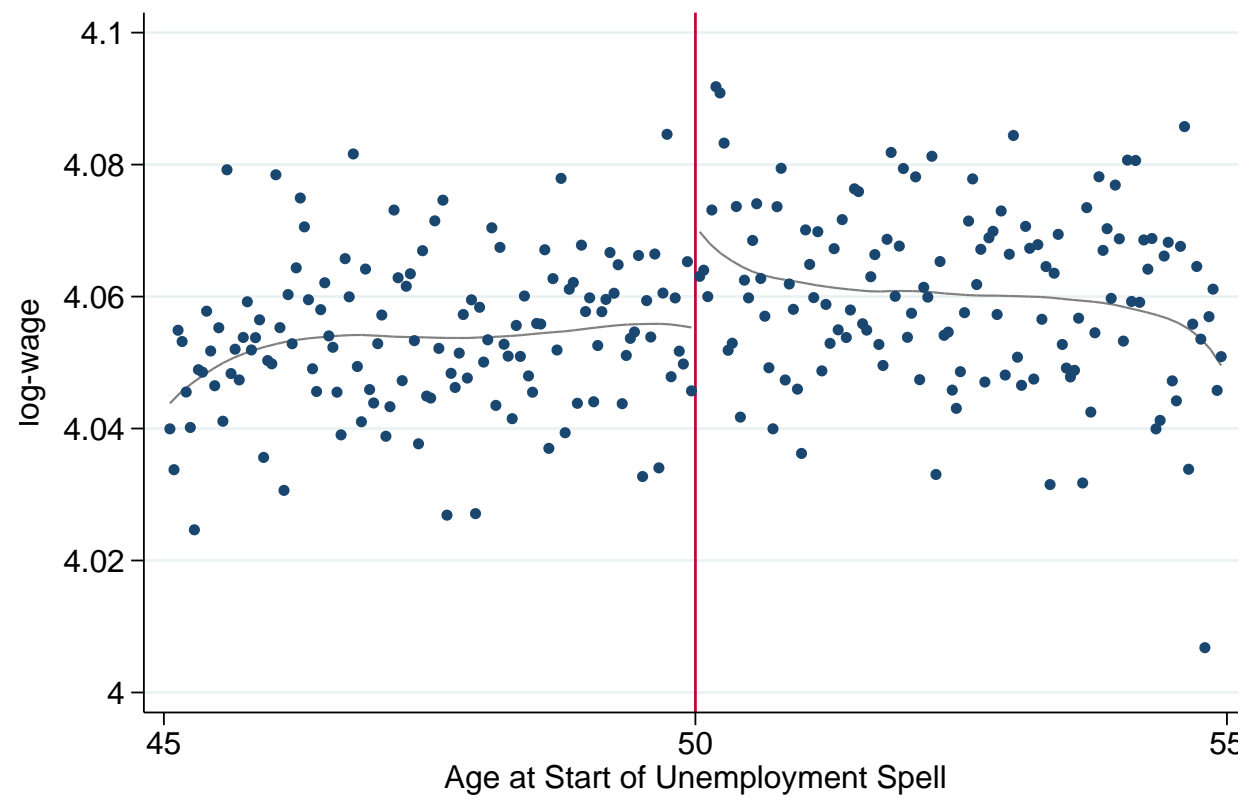

(b) Predicted Log Wage

Notes: This figure shows the smoothness of new UI benefit entries and predicted log wage around the age cutoff 50. Figure a) plots the frequency of new UI benefit. Figure b) plots the predicted daily log wage of the last employment spell from an OLS regression on predetermined covariates within a binize of two weeks. Explanatory variables are dummies for nationality, gender, children, marital status, East Germany and six educational groups, the duration till take-up, actual experience, occupational-, industry- and establishment tenure as well as seasonal (monthly) controls. 
Figure 2: UI Benefit and Nonemployment Durations of UI Spells around Age Cutoff for Potential UI Duration

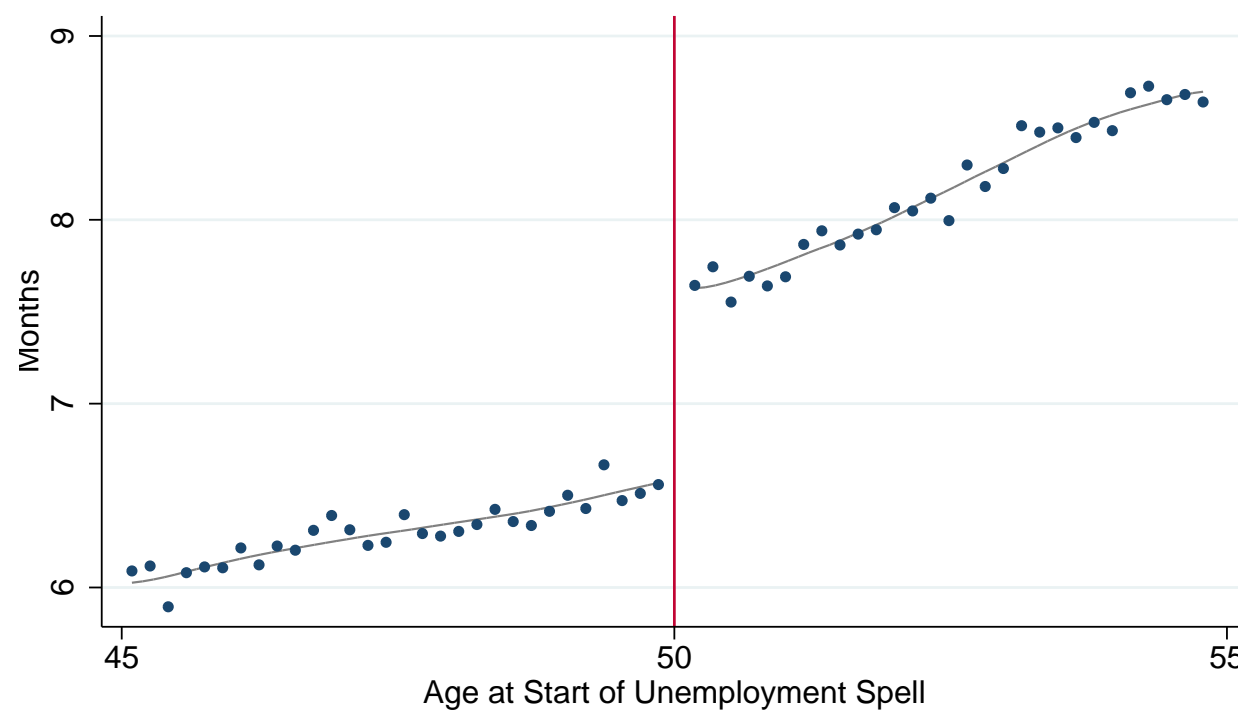

(a) UI Benefit Duration

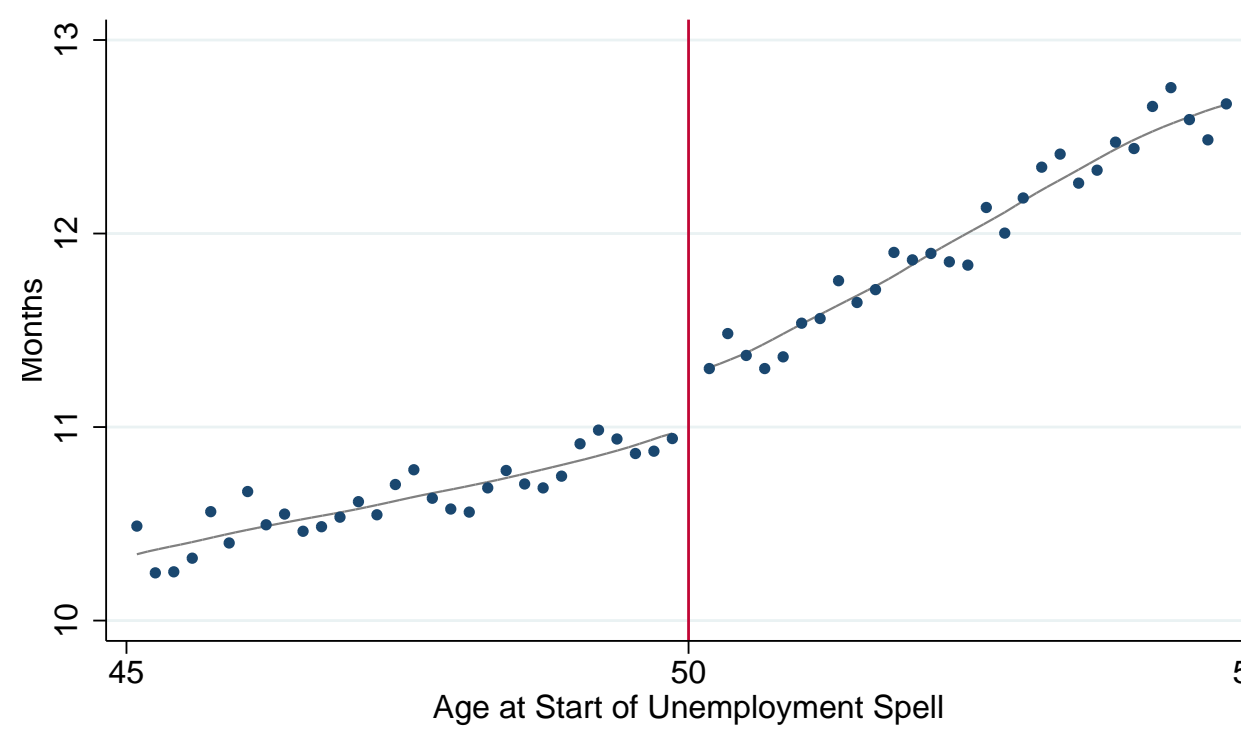

(b) Nonemployment Duration

Notes: This figure shows cross-sectional RD plots for the number of days in UI benefit receipt and the number of days in nonemployment (capped at 18 months). Binsize is set to 60 days. 
Figure 3: Unemployment Exit Hazard and Survivor Function around Age Cutoff for Potential UI Duration

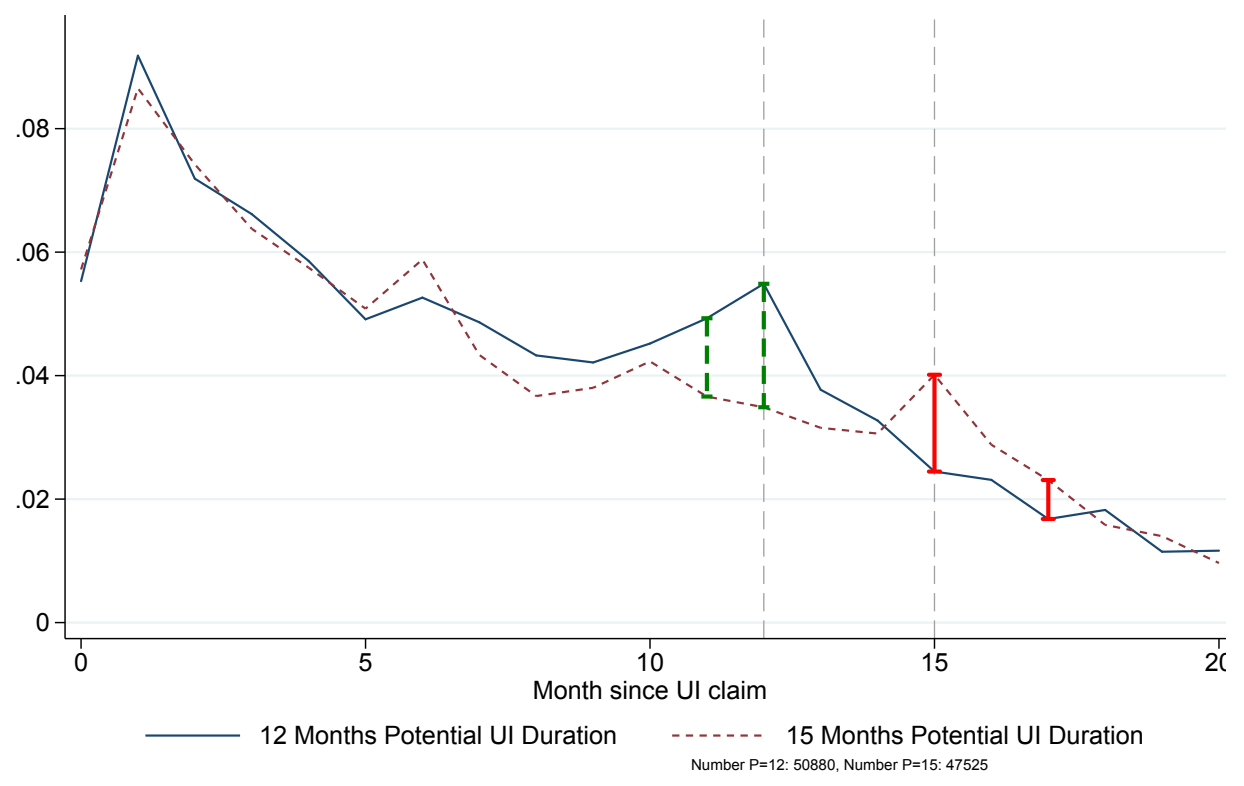

(a) Exit Hazard from Unemployment

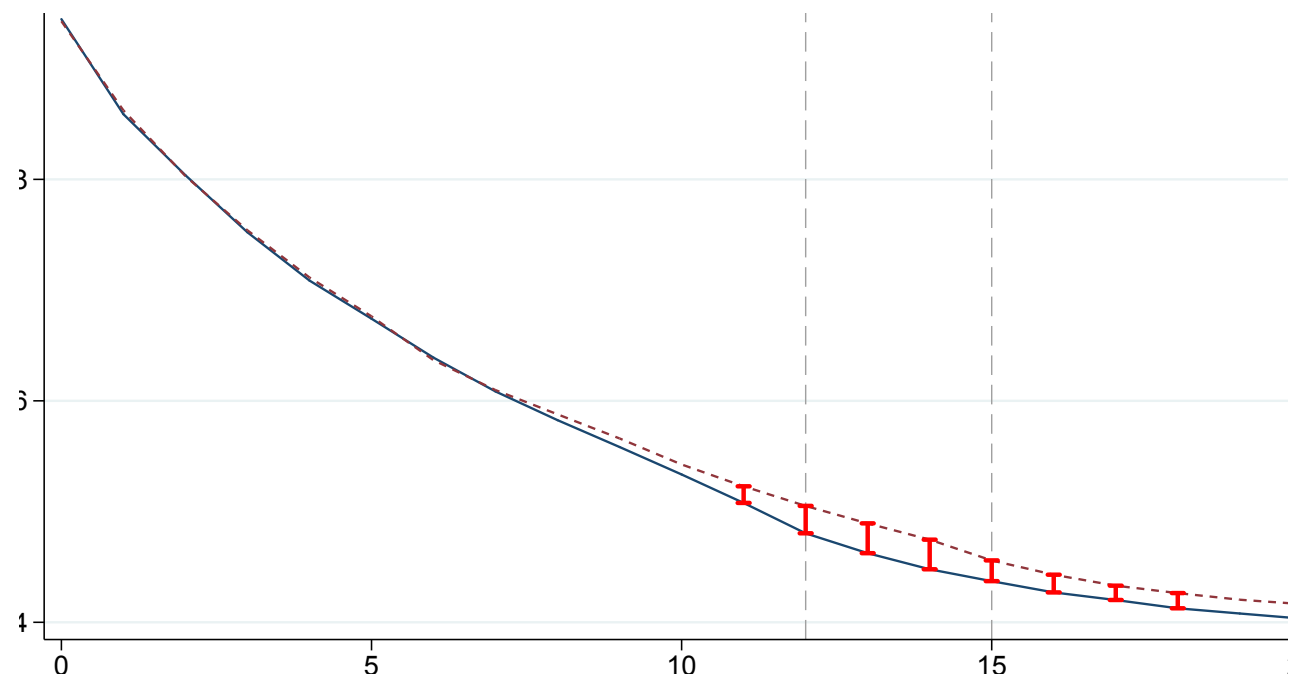

(b) Survivor Function

Notes: This figure shows estimates of the monthly hazard- and survival rates for both eligibility durations over the spell of UI benefit receipt. The blue solid line shows monthly point estimates of the 12-, the red dashed line of the 15 months eligibility duration. 
Figure 4: Contacts with Caseworkers around UI Cutoff

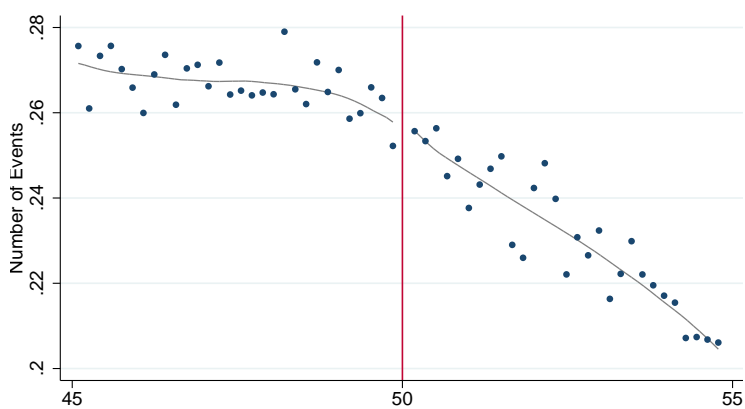

(a) Invitations

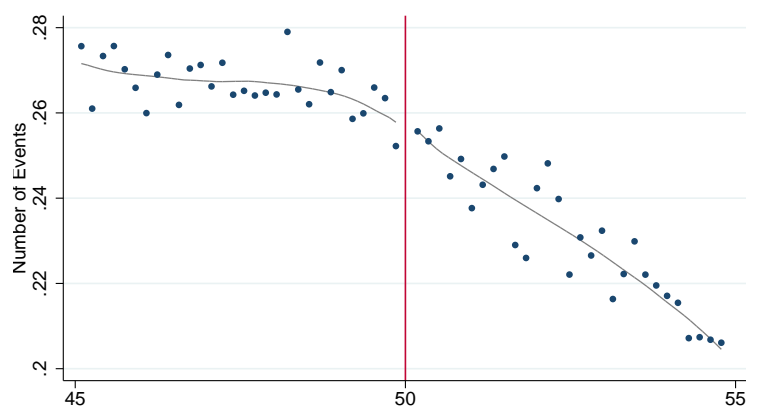

(c) Integration Contracts

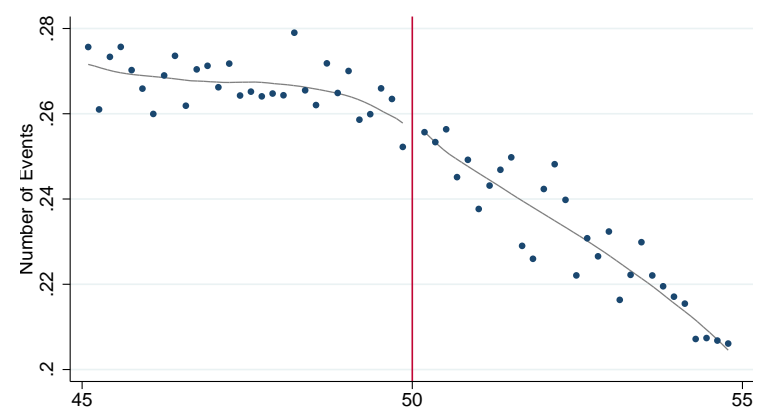

(b) Vacancy Referrals

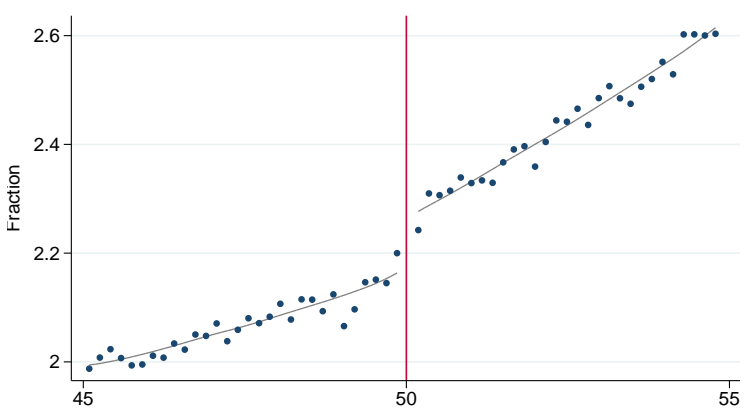

(d) Labor Market Profile (index)

Notes: This figure shows cross-sectional RD plots for caseworker contacts around the age cutoff 50. The outcome variables are measured as number of contacts per UI benefit receipt within the first twelve month of UI benefits for figure a) - c), and the assigned index value of the four relevant labor market profiles (where one means good prospects and four bad prospects) at the beginning UI entry for figure $\mathrm{d}$ ). The binsize is set to 60 days. 
Figure 5: Participation in ALMP of UI Spells around Age Cutoff for Potential UI Duration

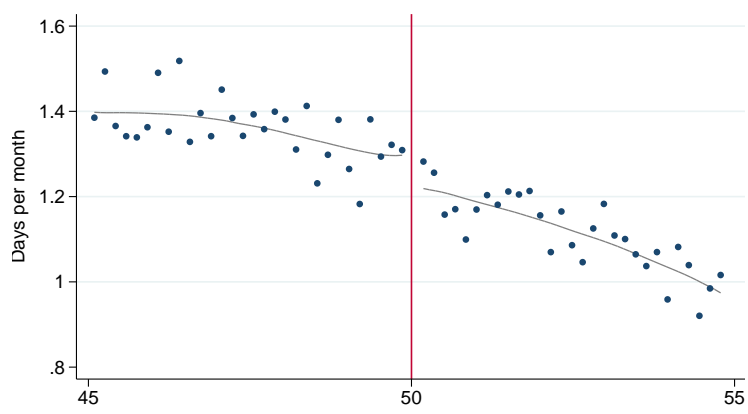

(a) Education Programms

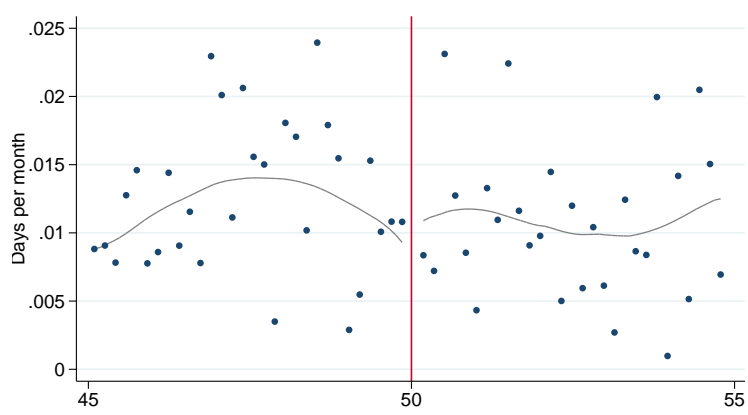

(c) Public Employment Programs

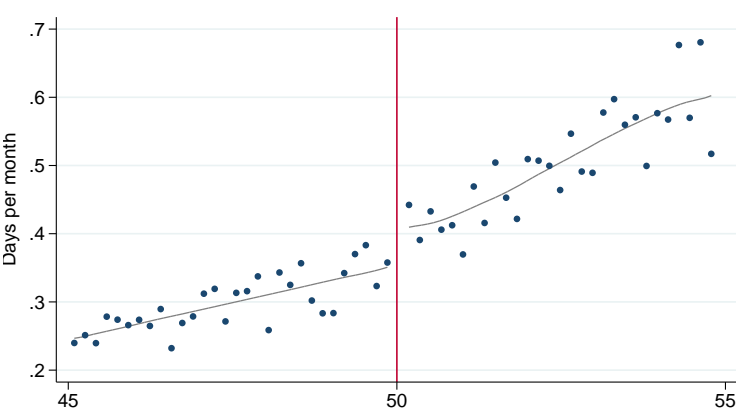

(b) Placement Services

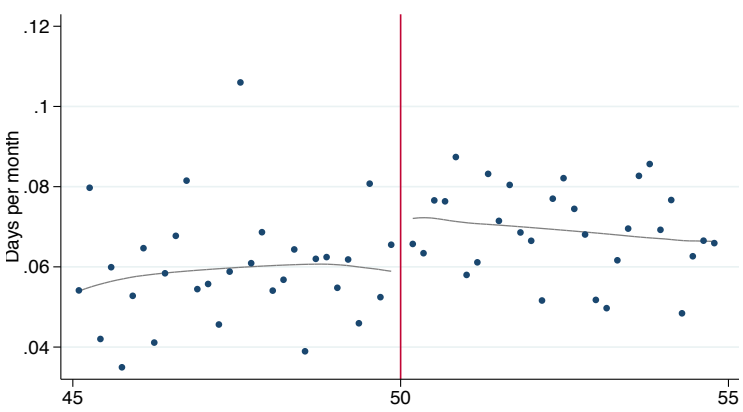

(d) Mixed ALMPs

Notes: This figure shows cross-sectional RD plots for training- and other ALMP programs around the age cutoff 50. The outcome variables are measured in days per month of UI benefit receipt within the first twelve month of UI. The binsize is set to 60 days. 
Figure 6: The Effect of Potential UI Durations on Caseworker Interactions Throughout the Unemployment Spell

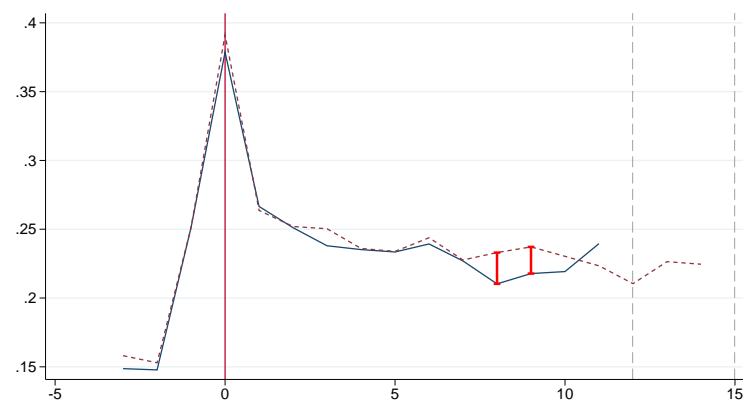

(a) Contracts

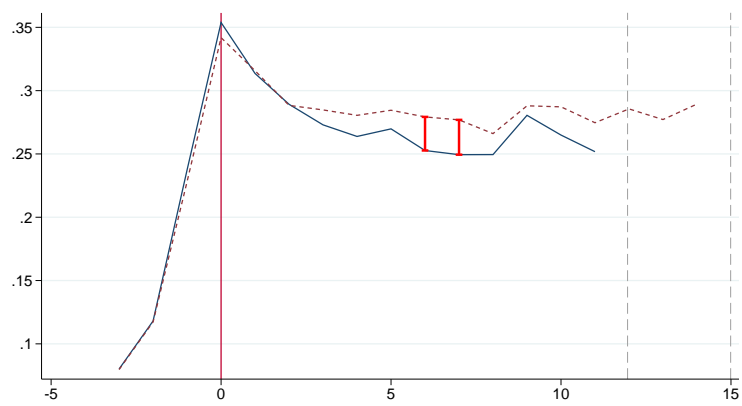

(c) Vacancy Referrals

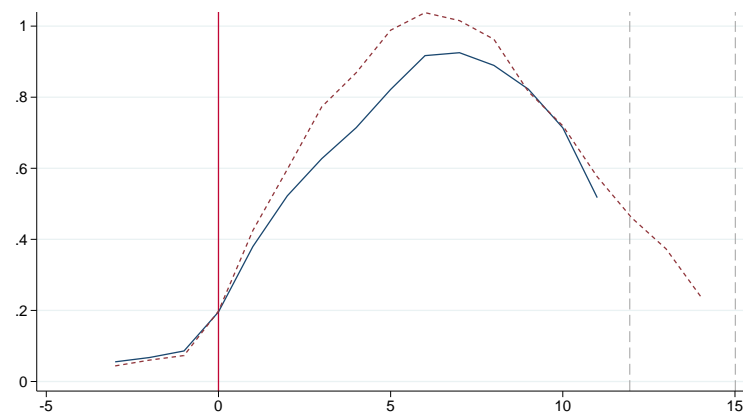

(e) Placement Services

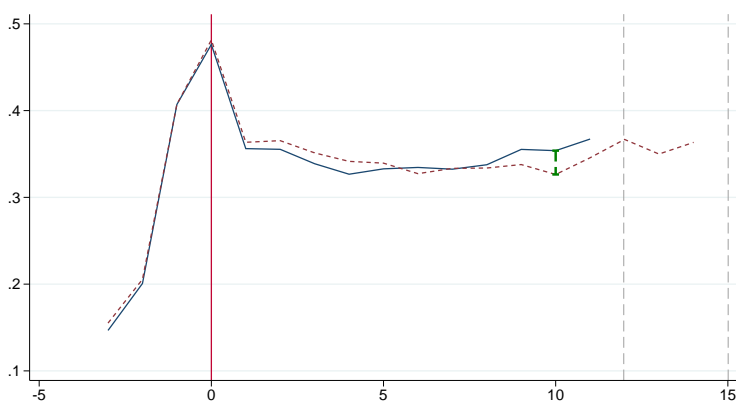

(b) Invitations

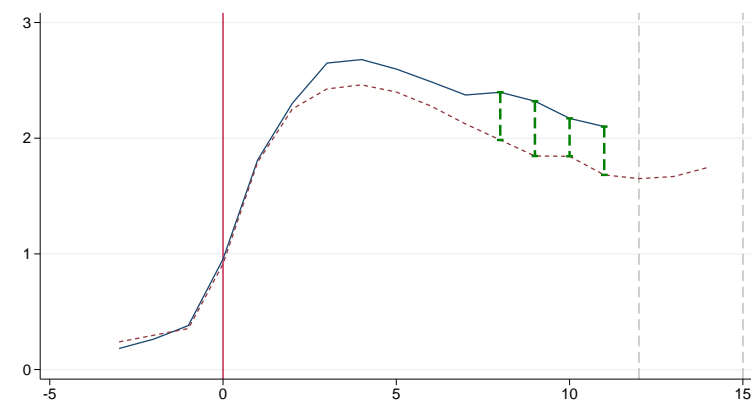

(d) Training Programms

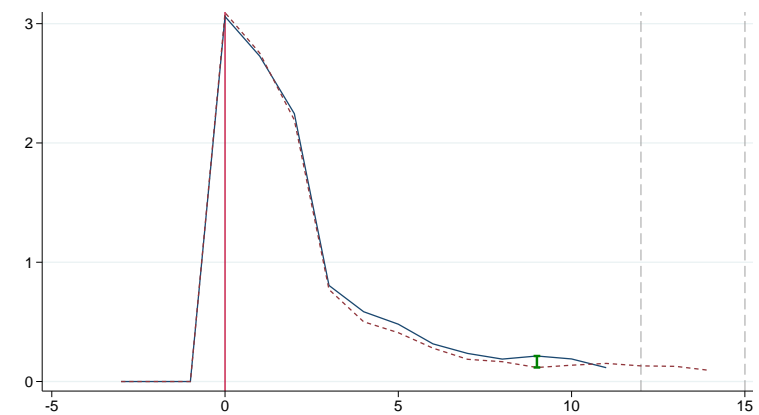

(f) Sanctions

Notes: This figure shows estimated counseling/monitoring intensities over the spell of UI benefit receipt (conditioned on receiving still UI benefits) for both eligibility durations. The blue solid line indicate estimates for 12-, the red dashed line estimates for the 15 months eligibility duration. Vertical bars indicate significant differences on the $5 \%$ significance level for the respective months. Figure a) - c) shows the number of interactions per months on UI, figure d) - f) number of days in the relative month. 